
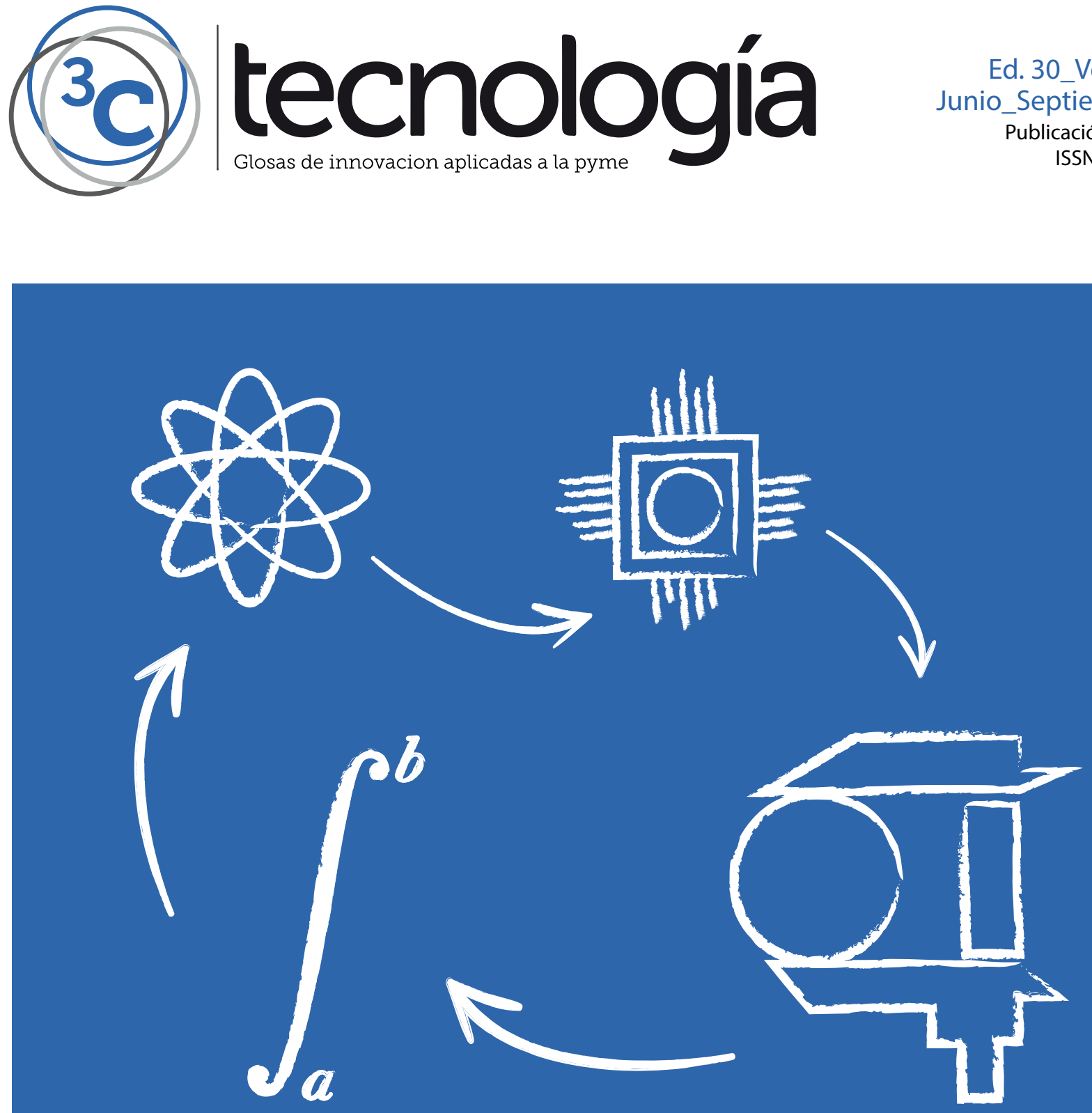


\section{C Tecnología. Glosas de innovación aplicadas a la pyme.}

Periodicidad trimestral. Quarterly periodicity.

Edición 30, Volumen 8, Número 2 (Junio - Septiembre '19). Edition 30, Volume 8, Issue 2 (fune - September '19).

Tirada nacional e internacional. National and internacional circulation.

Artículos revisados por el método de evaluación de pares de doble ciego. Articles reviewed by the double blind peer evaluation method.

ISSN: $2254-4143$

$\mathrm{N}^{\mathrm{o}}$ de Depósito Legal: A 268-2012

DOI: http://dx.doi.org/10.17993/3ctecno/2019.v8n2e30

Edita:

Área de Innovación y Desarrollo, S.L.

C/ Els Alzamora 17, Alcoy, Alicante (España)

Tel: 965030572

info@3ciencias.com _www.3ciencias.com

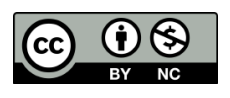

Todos los derechos reservados. Se autoriza la reproducción total o parcial de los artículos citando la fuente y el autor. This publication may be reproduced by mentioning the source and the authors. Copyright (C) Área de Innovación y Desarrollo, S.L. 


\section{(3) tecnología}




\section{CONSEJO EDITORIAL}

$\begin{array}{ll}\text { Director } & \text { Víctor Gisbert Soler } \\ \text { Editores adjuntos } & \text { María J. Vilaplana Aparicio } \\ & \text { Maria Vela Garcia } \\ \text { Editores asociados } & \text { David Juárez Varón } \\ & \text { F. Javier Cárcel Carrasco }\end{array}$

\section{CONSEJO DE REDACCIÓN}

Dr. David Juárez Varón. Universidad Politécnica de Valencia (España)

Dr. Martín León Santiesteban. Universidad Autónoma de Occidente (México)

Dr. F. Javier Cárcel Carrasco. Universidad Politécnica de Valencia (España)

Dr. Alberto Rodríguez Rodríguez. Universidad Estatal del Sur de Manabí (Ecuador)

\section{CONSEJO ASESOR}

Dra. Ana Isabel Pérez Molina. Universidad Politécnica de Valencia (España)

Dr. Julio C. Pino Tarragó. Universidad Estatal del Sur de Manabí (Ecuador)

Dr. Jorge Francisco Bernal Peralta. Universidad de Tarapacá (Chile)

Dr. Roberth O. Zambrano Santos. Instituto Tecnológico Superior de Portoviejo (Ecuador)

Dr. Sebastián Sánchez Castillo. Universidad de Valencia (España)

Dra. Sonia P. Ubillús Saltos. Instituto Tecnológico Superior de Portoviejo (Ecuador)

Dr. Jorge Alejandro Silva Rodríguez de San Miguel. Instituto Politécnico Nacional (México) 


\section{CONSEJO CIENTÍFICO TÉCNICO}

Área téxtil

Área financiera

Organización de empresas y RRHH

Estadística; Investigación operativa

Economía y empresariales

Sociología y Ciencias Políticas

Derecho

Ingeniería y Tecnología

Tecnologías de la Información y la Comunicación

Ciencias de la salud
Dr. Josep Valldeperas Morell

Universidad Politécnica de Cataluña (España)

Dr. Juan Ángel Lafuente Luengo

Universidad Faime I (España)

Dr. Francisco Llopis Vañó

Universidad de Alicante (España)

Dra. Elena Pérez Bernabeu

Universidad Politécnica de Valencia (España)

Dr. José Joaquín García Gómez

Universidad de Almería (España)

Dr. Rodrigo Martínez Béjar

Universidad de Murcia (España)

Dra. María del Carmen Pastor Sempere Universidad de Alicante (España)

Dr. David Juárez Varón

Universidad Politécnica de Valencia (España)

Dr. Manuel Llorca Alcón

Universidad Politécnica de Valencia (España)

Dra. Mar Arlandis Domingo

Hospital San Fuan de Alicante (España) 


\section{OBJETIVO EDITORIAL}

La Editorial científica 3Ciencias pretende transmitir a la sociedad ideas y proyectos innovadores, plasmados, o bien en artículos originales sometidos a revisión por expertos, o bien en los libros publicados con la más alta calidad científica y técnica.

\section{NUESTRO PÚBLICO}

- Personal investigador.

- Doctorandos.

- Profesores de universidad.

- Oficinas de transferencia de resultados de investigación (OTRI).

- Empresas que desarrollan labor investigadora y quieran publicar alguno de sus estudios.

\section{COBERTURA TEMÁTICA}

3G Tecnología es una revista de carácter científico - social en la que se difunden trabajos originales que abarcan la Arquitectura y los diferentes campos de la Ingeniería, como puede ser Ingeniería Mecánica, Industrial, Informática, Eléctrica, Agronómica, Naval, Física, Química, Civil, Electrónica, Forestal, Aeronáutica y de las Telecomunicaciones.

\section{INFORMACIÓN PARA AUTORES}

Toda la información sobre el envío de originales se puede encontrar en el siguiente enlace: http://www.3ciencias.com/normas-de-publicacion/instrucciones-para-el-envio-de-articulos/ 


\section{PUBLISHING GOAL}

3Ciencias wants to transmit to society innovative projects and ideas. This goal is reached thought the publication of original articles which are subdue to peer review or thorough the publication of scientific books.

\section{OURTARGET}

- Research staff.

- $\quad$ PhD students.

- $\quad$ Professors.

- $\quad$ Research Results Transfer Office.

- Companies that develop research and want to publish some of their works.

\section{TEMATIC COVERAGE}

3C Tecnología is a scientific - social journal in which original works that cover Architecture and the different fields of Engineering are disseminated, such as Mechanical, Industrial, Computer, Electrical, Agronomic, Naval, Physics, Chemistry, Civil, Electronics, Forestry, Aeronautics and Telecommunications.

\section{INSTRUCTIONS FOR AUTHORS}

All information about sending originals can be found at the following link:

https://www.3ciencias.com/en/regulations/instructions/ 


\section{INDIZADO POR}

\section{INDEXED BY}

Plataforma de evaluación de revistas
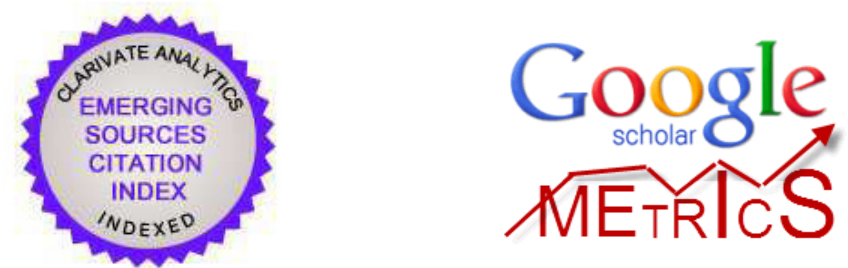

MIAR

Matriu d'Informació

per a l'Avaluació de Revistes

Bases de datos internacionales selectivas

\section{EBSCOhost}

\section{isoce [I] \\ Business Source 뱁 Premier}

$$
\text { OAJl Open Academic }
$$
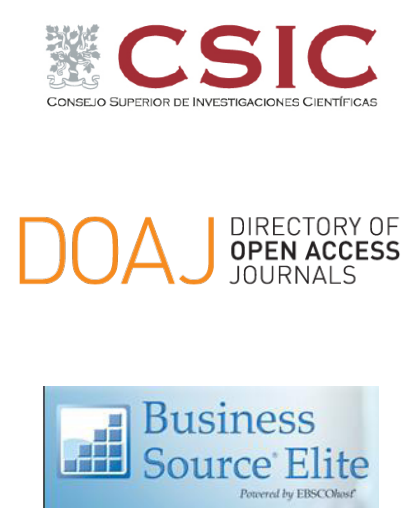
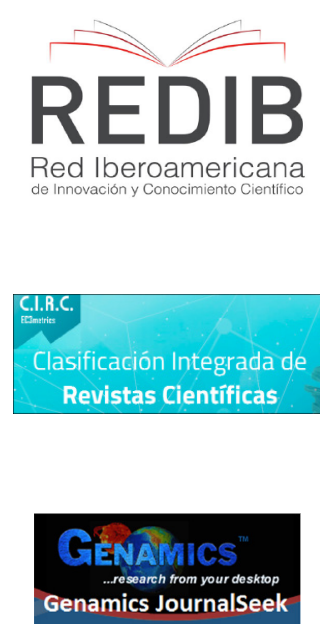
INDIZADO POR

INDEXED BY

Directorios selectivos

\section{latindex}

Hemerotecas selectivas

\section{O Dialnet}

Buscadores de literatura científica en acceso abierto

DULCINEA 
/SUMARIO/ 
Reingeniería del sistema de seguimiento de Demandas del Tribunal de Justicia Administrativo

Reengineering of the system for follow-up of claims of the court of administrative justice

Hernández Jiménez, A., Chávez Valdez, R. E., Benavides Delgado, J. R. y Figueroa Millán, P. E.

Blockchain vs ISO 9001:2015

Blockchain vs ISO 9001:2015

Gisbert Soler, V. y Pérez Molina, A. I.

Importancia del mantenimiento, aplicación a una industria textil y su evolución en eficiencia

Importance of maintenance, application to a textile industry and its evolution in efficiency

García Sierra, J., Cárcel Carrasco, J. y Mendoza Valencia, J.

Cómo aplicar "Value Stream Mapping” (VSM)

How to apply "Value Stream Mapping" (VSM)

García Cantó, M. y Amador Gandia, A.

Análisis de Causa Raíz. Técnicas y relación con los sistemas de gestión y las no conformidades

Root Cause analysis. Techniques and relationship with management systems and non-compliance

Poveda Catalán, J. y Guardiola Aparisi, M. 
/01/ 


\title{
REINGENIERÍA DEL SISTEMA DE SEGUIMIENTO DE DEMANDAS DEL TRIBUNAL DE JUSTICIA ADMINISTRATIVO
}

REENGINEERING OF THE SYSTEM FOR FOLLOWUP OF CLAIMS OF THE COURT OF ADMINISTRATIVE JUSTICE

\author{
Andrés Hernández Jiménez \\ Estudiante de Maestría del Tecnológico Nacional de México, \\ Instituto Tecnológico de Colima, México.
}

E-mail: dreamsroom3@gmail.com ORCID: https://orcid.org/0000-0002-5958-2098

\begin{abstract}
Ramona Evelia Chávez Valdez
Profesor adjunto de la División de Estudios de Posgrado del Tecnológico Nacional de México,

Instituto Tecnológico de Colima, México.

E-mail: echavez@itcolima.edu.mx ORCID: https://orcid.org/0000-0002-5697-6825
\end{abstract}

J. Reyes Benavides Delgado

Profesor adjunto de la División de Estudios de Posgrado del Tecnológico Nacional de México,

Instituto Tecnológico de Colima, México.

E-mail: rbenavides@itcolima.edu.mx ORCID: https://orcid.org/0000-0002-6190-5933

Patricia Elizabeth Figueroa Millán

Profesor adjunto de la División de Estudios de Posgrado del Tecnológico Nacional de México,

Instituto Tecnológico de Colima, México.

E-mail: patricia.figueroa@itcolima.edu.mx ORCID: https://orcid.org/0000-0001-7562-7578

Recepción: 06/02/19 Aceptación: 06/06/19 Publicación: 14/06/19

Gitación sugerida:

Hernández Jiménez, A., Chávez Valdez, R. E., Benavides Delgado, J. R. y Figueroa Millán, P. E. (2019). Reingeniería del sistema de seguimiento de Demandas del Tribunal de Justicia Administrativa. 3C Tecnología. Glosas de innovación aplicadas a la pyme, 8(2), pp. 12-35. doi: http://dx.doi.org/10.17993/3ctecno/2019. v8n2e30.12-35 


\section{RESUMEN}

En esta investigación se realizó el proceso de reingeniería para corregir fallos y aplicar mejoras al Sistema de Seguimiento de Demandas (SiSeDe) implantado en el Tribunal de Justicia Administrativa del estado de Colima, México. Se trata de un sistema de información con características web que facilita el seguimiento a los proyectos de sentencias, enfocándose en un módulo de indicadores de productividad para mejorar los tiempos de atención a los juicios de carácter administrativo. Para controlar el proceso de ingeniería de software se empleó el Proceso Unificado Ágil, por sus características para manejar proyectos pequeños, cambiantes y de cierto riesgo. Los resultados residen en un software que presenta con elementos estadísticos el tiempo de atención a la demanda, considerando métricas de evaluación de procesos por tiempo, además de las establecidas por la Ley Administrativa del estado de Colima, México. Los actores responsables de la impartición de justicia administrativa, con apoyo de las señales de semáforos, pueden visualizar en el sistema la productividad de los actores que intervienen en la demanda, identificando cuántas demandas han atendido y cuántas se tienen en prevención o en rezago. Estos datos permiten a la dependencia incorporar estrategias para mejorar la atención de los procesos de justicia.

\section{PALABRAS CLAVE}

Indicadores, Juicios, Productividad, Reingeniería, Seguimiento. 


\section{ABSTRACT}

In this research, the process of reengineering was carried out to correct faults and apply improvements to the Follow-up System of Demands (SiSeDe) implanted in the Administrative Court of the State of Colima, Mexico. It is an information system with web features that facilitates the follow-up of sentencing projects, focusing on a module of productivity indicators to improve the time of attention to administrative trials. To control the software engineering process, the Agile Unified Process was used, due to its characteristics to handle small, changing and risky projects. The results reside in a software that presents the time of attention to the demand with statistical elements, considering metrics of evaluation of processes by time in addition to those established by the Administrative Law of the State of Colima, Mexico. The actors responsible for administering administrative justice, with the support of signals like traffic lights, can visualize in the system the productivity of the actors that intervene in the demand, identifying how many demands they have attended and how many are in prevention or in lag of attendance. These data allow the administrative personal to incorporate strategies to improve the attention of the justice processes.

\section{KEYWORDS}

Follow-up, Indicators, Productivity, Reengineering, Trials. 


\section{INTRODUCCIÓN}

Cuando se obtiene un producto de tecnología se asumen riesgos en garantía del mismo, uno de los puntos que más se observan en el desarrollo del software es la obsolescencia del mismo, es decir, comienzan las fallas, existen errores que tardan en repararse y la solución vigente deja de ser la solución actual para la problemática para la que se adquirió (Sommerville, 2005). Por ejemplo, un software personalizado es un elemento del que no tan fácilmente se dispone o se puede dejar de utilizar, por lo tanto, es necesario reconstruirlo, con la finalidad de crear un producto con una funcionalidad nueva, que presente un mejor rendimiento y fiabilidad, que tenga un mantenimiento mejorado, esto es lo que se conoce como reingeniería (Sicilia y De la Morena, 2009).

Un software personalizado es un elemento del que no tan fácilmente se dispone o se puede dejar de utilizar, por lo tanto, es necesario reconstruirlo, con la finalidad de crear un producto con una funcionalidad nueva.

El principal enfoque que se aplica a la reingeniería es aquel que está dirigido a las actividades de mantenimiento: El entendimiento (predecir), la reparación (corregir), mejoramiento (perfeccionar) y la evolución (adaptar) (Olsem, Sittenauer, Dawood, y Rasmussen, 1995). De la misma forma, Sicilia (2009) establece que dentro de los beneficios que aporta la reingeniería a un producto se encuentran:

- Reducir riesgos evolutivos en la organización.

- Ayudar a recuperar las inversiones en software.

- Hacer que el software sea más fácilmente modificable.

- Catalizar la automatización del mantenimiento del software.

Para la implementación de mejoras en un sistema se deben considerar cuatro preguntas esenciales: ¿Qué transformar?, ¿Por qué transformar?, ‘CCómo transformar? y ¿Sobre qué transformar?; la primer pregunta se rige sobre los elementos que definen el proceso a realizar con ayuda de los diferentes procesos de reingeniería (ingeniería inversa, redocumentación, estructuración y modernización), la segunda se refiere al objetivo por el que se hace la mejora, la tercera se enfoca a las técnicas utilizadas para realizar 
la transformación, y la última pregunta se refiere al producto sobre el cual se aplicarán las mejoras (Jürgen, Franz, Volker, y Andreas, 2005). Teniendo esto en cuenta, se puede estimar que el proceso de reingeniería de un producto de software atrae beneficios a la organización, ya que puede incrementar la funcionalidad del sistema.

Por otro lado, otro aspecto que define a las empresas es su productividad, entendida como aquella que establece la relación entre lo producido y los medios empleados, tales como la mano de obra, materiales, energía, etc. (RAE, 2017); en cambio, en el sentido de una empresa, March y Sutton (1997) determinan que el desempeño de toda organización se presenta en forma de un constructo clave en la dirección estratégica de la misma, por lo que se puede establecer que en toda empresa u organización uno de los principales fines es el conducirse hacia la eficiencia organizacional; de igual forma, Mejía (2007) menciona que este factor puede contabilizarse con la ayuda de indicadores que sirvan de referencia para identificar puntos clave que requieran modificarse, con un enfoque en los factores que incidan en el desempeño de procesos, tales como la calidad, seguridad, costos, tiempos, la planeación y el control, esto con el fin de alcanzar el desarrollo óptimo de la misma.

Considerando lo establecido en la página Workmeter (2012) los indicadores de productividad son aquellas variables que nos ayudan a identificar algún defecto o imperfección que exista en el proceso en el que elaboramos un producto o se ofrece un servicio, lo que refleja la eficiencia en el uso de los recursos generales y recursos humanos de la empresa, estos pueden ser cualitativos o cuantitativos, la fórmula del cálculo de la productividad es el cociente entre la producción y el consumo, todo acorde al tipo de empresa a la que se está refiriendo.

Los aspectos anteriores fundamentan las razones por las cuales se establece la necesidad de aplicar la reingeniería al producto desarrollado por Fernández y Moreno (2017), el Sistema de Información para el Seguimiento de las Demandas (SiSeDe) con el que el Tribunal de Justicia Administrativa del Estado de Colima (TJA) antes conocido como Tribunal de lo Contencioso Administrativo del Estado de Colima, México, realiza sus actividades, esto con la finalidad de mejorar la sistematización de los procesos implementados y medir la productividad del organismo en la impartición de justicia. Esta dependencia se encarga de gestionar los juicios administrativos que interponen los ciudadanos por la no conformidad con la prestación de algún servicio asignado a dependencias gubernamentales con ámbito local o estatal. 
Para la reestructuración del SiSeDe se utilizaron tecnologías de información que facilitaran la reingeniería, orientadas al trabajo de migración de datos, de asistencia y de diseño, de pruebas y de validación del sistema, así como la integración de indicadores que miden tiempos de proceso para crear un módulo que evalúe la productividad de los actores que intervienen en el seguimiento de la demanda.

Para la integración de indicadores se establecieron aquellos que evalúan tiempos de proceso como lo es la métrica de rango DAU/MAU (por sus siglas en ingles de Monthly Active Users y Daily Active Users), las cuales se definen como la Proporción de Usuarios Activos Diarios (DAU) a Usuarios Activos Mensuales (MAU) y que mide la rigidez de su producto, es decir, la frecuencia con la que la gente interactúa con un producto (GECKOBOARD, 2017), otra de ellas es la que se establece en la Ley de Justicia Administrativa del Estado de Colima, México (H. Congreso del Estado de Colima, 2018) y finalmente aquellas establecidas por los propios elementos del tribunal.

En referencia a los procesos de migración y ordenamiento de datos, para los cuales existe el término ETL, entendido como el proceso de Extraction, Transformation and Load (Extracción, Transformación y Carga) (Microsoft, 2018), permite obtener los antecedentes de una o más fuentes de almacenamiento, procesarlos, reformatearlos y/o limpiarlos y almacenarlos nuevamente en una base de datos; dicho proceso fue asistido por la herramienta Talend Open Studio (Talend, 2018), esta última es una herramienta de código abierto desarrollada bajo el lenguaje de programación Java ${ }^{\circledR}$. Para las primeras etapas de diseño de las nuevas interfaces se utilizó la versión de prueba versión de prueba de un software de ayuda de diseño denominada Balsamiq Muckups, ya que ofrece la misma velocidad y la misma sensación que dibujar con un lápiz, pero con la ventaja del medio digital: arrastrar y soltar para cambiar el tamaño y reorganizar elementos, hacer cambios sin volver a empezar desde cero (Balsamiq Studios ,LLC, 2018). El uso de esta herramienta permite el desarrollo de trazos o plantillas que sirven como referencia para plasmar las ideas de diseño tanto de diseñadores o de usuarios, las cuales funcionan como reseña para que el programador transforme esas ideas y bocetos a una interface que estará cercana a la realidad de lo que los clientes esperan. Para finalizar, las pruebas que se realizaron al producto de reingeniería se basaron en aquellas aplicadas en el proceso de desarrollo de software, denominadas pruebas de caja blanca y caja negra, Sommerville (2005) define que las pruebas en un software realizadas sobre las funciones internas de un módulo son aquellas conocidas como pruebas de caja blanca, en cambio, aquellas que se enfocan en los requisitos funcionales desde el exterior del módulo o a un conjunto mayor 
de módulos en lo que se considera la integración final del sistema, para esto se utilizó una herramienta incluida en el framework de programación denominada PHPUnit (Bergmann, 2018) en su versión 4.8 que permitió realizar todas las pruebas unitarias y de integración del sistema.

\section{METODOLOGÍA}

El proceso de reingeniería se basó en la metodología del Proceso Unificado Ágil (PUA), la cual es una versión simplificada de la metodología de Proceso Racional Unificado, en donde se describe un enfoque simple y fácil de entender para el desarrollo de software de aplicaciones de negocio utilizando técnicas y conceptos ágiles, las cuales incluyen el desarrollo guiado por pruebas, el modelado ágil , la gestión de cambio ágil y la refactorización de base de datos para mejorar la productividad del producto informático (Ambler, 2014).

Acorde a lo establecido por (Ambler, 2014), la metodología PUA que presenta la Figura 1, consta de cuatro fases que el proyecto atiende de forma iterativa e incremental:

1. Iniciación: se identifica el alcance inicial del proyecto, una arquitectura potencial para el sistema y obtener, si procede, financiación para el proyecto y la aceptación por parte de los promotores del sistema.

2. Elaboración: esta fase permite identificar y validar la arquitectura del sistema.

3. Construcción: el objetivo de esta fase consiste en construir software desde un punto de vista incremental basado en las prioridades de los participantes.

4. Transición: en esta fase se valida y despliega el sistema en el entorno de producción. 


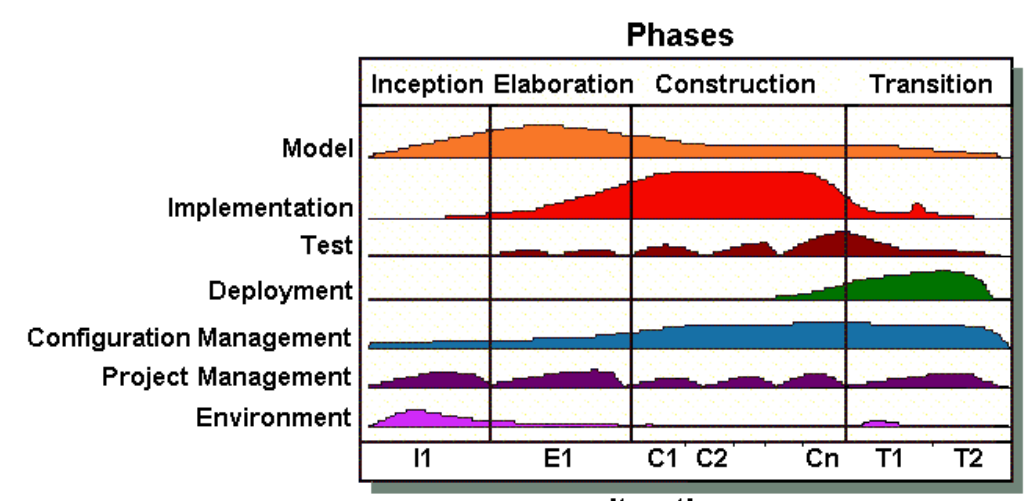

Copyright 2005 Scott W. Ambler

Iterations

Figura 1. Ciclo de vida de la metodología PUA. Fuente: http://www.ambysoft.com/unifiedprocess/agileUP.html, 2005.

A lo largo de las cuatro fases, se desarrollan actividades relativas a siete disciplinas de manera iterativa:

- Modelado: su objeto es entender la lógica de negocio de la aplicación, el dominio del problema del proyecto e identificar una solución viable para el dominio del problema.

- Implementación: transformar los modelos en código ejecutable y realizar pruebas básicas, en particular pruebas unitarias.

- Pruebas: realizar una evaluación de los objetivos para asegurar la calidad; incluye encontrar defectos, validar que el sistema funciona como fue diseñado y verificar que los requisitos se cumplan.

- Despliegue: planear la entrega del sistema y ejecutar el plan para hacer que el sistema quede disponible para los usuarios finales.

- Gestión de la configuración: gestionar el acceso a los artefactos del proyecto. Esto incluye, además de la traza de versiones de los artefactos, el control de cambios y la gestión de los mismos.

- Gestión del proyecto: dirige las actividades que tienen lugar dentro del proyecto, incluyendo gestión de riesgos, dirección del personal y coordinación. 
- Entorno: apoyar el resto del esfuerzo asegurando que los procesos, métodos y herramientas están disponibles para el equipo cuando los necesitan.

Esta metodología permitió controlar el proceso de ingeniería de software, así en la fase de iniciación se determinó el alcance y la arquitectura del sistema mediante la recopilación de los requerimientos, se establecieron además las prioridades en los casos de uso que determinan las funcionalidades requeridas en el sistema; en la fase de elaboración se realizaron los modelados de clases, datos e interfaces, que corresponden a los procesos de reingeniería del sistema y otros a la inclusión de los indicadores de productividad del proceso de seguimiento de demanda, de acuerdo a las iteraciones definidas previamente; los modelos elaborados fueron implementados y probados en la fase de construcción donde se realizó la codificación necesaria para cumplir con los requerimientos, tanto actuales como anteriores del sistema, realizando pruebas de funcionalidad a cada una de las actividades programadas. Finalmente, en la fase de transición se desplegaron los resultados en un medio local para posteriormente ser colocados en el servidor de producción.

La metodología PUA permitió controlar el proceso de ingeniería de software, desde la fase de iniciación hasta la fase de transición.

\section{RESULTADOS}

\subsection{EL PROCESO DE REINGENIERÍA}

Para realizar el proceso de reingeniería se consideró la normatividad del TJA, la documentación del Sistema de Seguimiento de Demandas (SiSeDe) - reporte técnico, manual de usuario y código - a disposición del TJA. La principal razón para realizar el proceso de reingeniería fue el cambio estructural que recibió el TJA en razón a la estructura orgánica recientemente aprobada, la cual pasó de ser un organismo con estructura simple ( un magistrado para legislar y gestionar la legalidad y jurisprudencia en la dependencia) a una estructura compuesta (múltiples magistrados que rigen y gestionan la legalidad y jurisprudencia en la dependencia) lo cual hizo necesaria la reingeniería del sistema de gestión SiSeDe, incorporando un módulo de indicadores de productividad dirigido a los magistrados para facilitar su trabajo. 
Otros de los aspectos que justifican la reingeniería son los encontrados con base al análisis del SiSeDe desarrollado por Fernández y Moreno (2017), mismos que reflejan la estructura del proceso de demanda, que implica el cambio del modelo organizacional de la institución, la liberación del proceso de seguimiento de demandas en línea en el estado de Colima, así como validaciones de los procesos de almacenamiento de datos, y finalmente la petición propia de los interesados de aplicar una mejora visual a las interfaces para hacer el sistema más intuitivo e interactivo al usuario.

Siguiendo los procesos de la reingeniería, para ser más específico, con ayuda de la ingeniería inversa, con base al cambio de requerimientos y de la estructura orgánica del TJA, así como la implementación de mejoras, presentamos la propuesta descrita en este artículo.

\subsection{REINGENIERÍA DE PROCESOS}

Apegados a la metodología, la fase de iniciación incluyó la reingeniería de procesos, donde se tomaron en cuenta los requerimientos establecidos en el sistema anterior, estos se compararon con el levantamiento de requisitos actuales, a fin de definir el alcance que permitiera elaborar los casos de uso que representan el comportamiento del sistema.

Aunado a esto, se recopiló información con ayuda de entrevistas individuales, asesoramiento, observación y la lectura de la documentación que se obtuvo del TJA, lo cual dio lugar a establecer estas premisas:

- El sistema debe permitir la correcta distribución de cargas de trabajo, esto está justificado en el cambio estructural del TJA, en el cual se cuenta con más personal del considerado en la versión anterior.

- El sistema debe simplificarse, evitar el uso excesivo de clics y que las interfaces sean más intuitivas al usuario, referenciando los medios de registro, navegación, y uso general del sistema.

- Se hace necesario regularizar y habilitar el sistema para la impartición de justicia en línea, permitiendo ingresar al sistema tanto a los trabajadores como a los usuarios interesados en el proceso de demanda, asegurándose que el uso del programa sea conforme a los procedimientos del proceso presencial en el TJA. 
- Se debe considerar una nueva clasificación en las demandas en la estructura de registro del sistema, aquellas de proceso simple como por ejemplo las resoluciones de multas de tránsito, y aquellas de proceso complejo que requieren mayor investigación, tiempo y recursos para solventarlas, lo que permite distribuir de forma correcta el punto anterior.

- EL sistema debe permitir que las notificaciones y resoluciones de cada uno de los procesos puedan realizarse ya sea por medio físico o por el medio digital.

Estas premisas están modeladas en el diagrama de casos de uso que se muestra en la Figura 2, como se observa se presentan el escenario general del funcionamiento del SiSeDe, donde el usuario puede ser público (demandante) o institución, quien presenta la demanda y la registra en el sistema; por su parte el Oficial de partes realiza la verificación de documentos y valida dicho registro. Una vez registrada la demanda el Secretario de Acuerdos revisa los documentos, los analiza y fundamenta la creación de un acuerdo, éste es notificado por el Actuario a los usuarios demandantes. Una vez que se cumplan los requisitos establecidos en los acuerdos se procede a generar un dictamen de sentencia, en el intervienen los Proyectistas con apoyo de los Magistrados, siendo éstos últimos los que tienen la decisión final sobre el veredicto de la sentencia, procediendo así a la ejecución de la misma. 


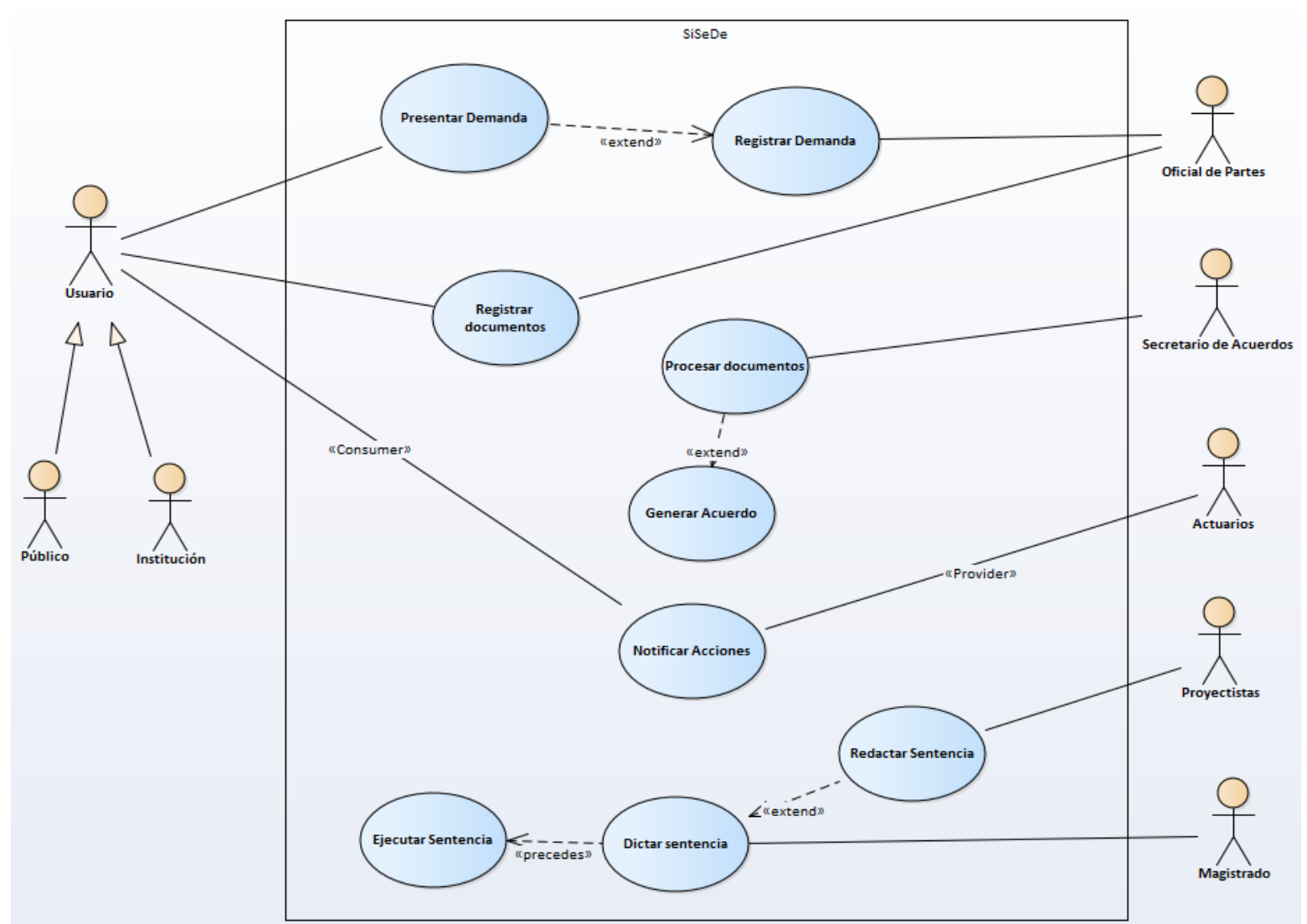

Figura 2. Diagrama de casos de uso del flujo de la demanda en el sistema SiSeDe. Fuente: elaboración propia.

\subsection{REINGENIERÍA EN EL MODELO DE DATOS}

La reingeniería en el modelo de datos implicó ajustes considerando las modificaciones estructurales de la organización y los procedimientos que marca la ley (H. Congreso del Estado de Colima, 2018), se establecieron las nuevas especificaciones en la base de datos; la Figura 3 muestra un fragmento del nuevo modelo, en donde sobresale la mejora en la estructura, ya que se añaden los procedimientos y funciones que conforman los indicadores de tiempo estipulados para medir la productividad del seguimiento de las demandas, esto se observa desde las tablas expediente, personas e instituciones, donde al incluir 
marcas de tiempo se hace posible la implementación del módulo de indicadores para determinar la semaforización de actividades de cada actor. Así, una vez colocada la demanda, se podrá medir cuanto tiempo estuvo en atención del oficial de parte, del secretario de acuerdos, del proyectista, entre otros actores. Dicho tiempo se contrastará con lo indicado por la ley y se emitirá el semáforo con su color correspondiente; esto dará lugar a crear estrategias para que la demanda avance a su siguiente estado.
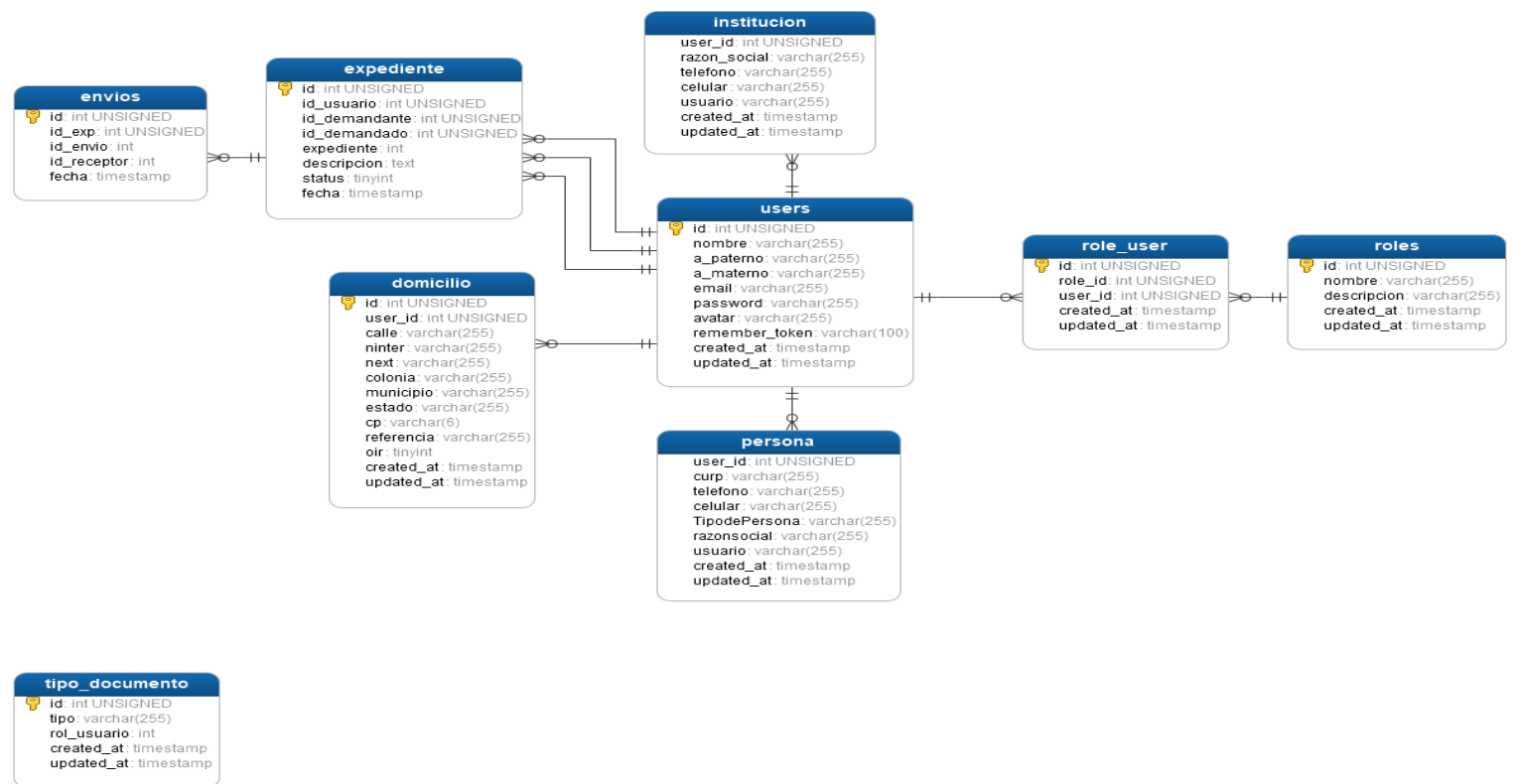

Figura 3. Fragmento del modelo de base de datos después de la Reingeniería. Fuente: elaboración propia.

Por otra parte, se tuvo especial cuidado en la migración de los datos, ya que al realizar una reestructuración de un sistema es necesario visualizar la necesidad del mantenimiento al mismo, esto incluye la información existente en él. El proceso de transformación de datos se separó en trabajos enfocados a secciones específicas de nuestro diseño de base de información como se puede ver en la Figura 4, la cual representa la transformación de la información de los usuarios registrados en el sistema anterior para acoplarse al nuevo modelo con el apoyo de la herramienta Talend Open Studio en su versión 6.2.1. 


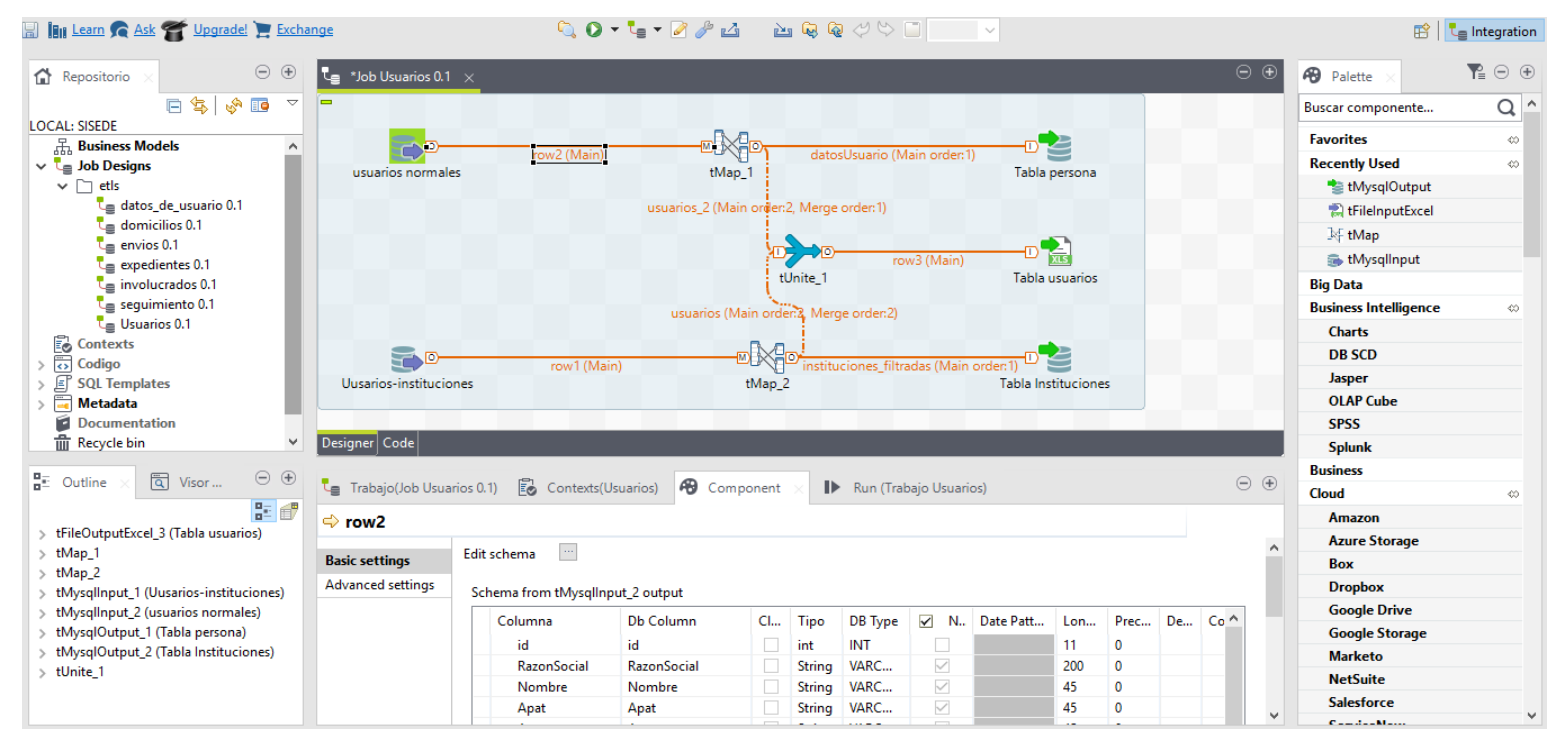

Figura 4. Trabajo ETL de integración de los datos de la tabla Usuarios. Fuente: elaboración propia.

\subsection{REINGENIERÍA DE LAS INTERFACES DE USUARIO (GUI)}

Para definir la nueva estructura de las interfaces de usuario se tomaron en consideración los requerimientos y solicitudes de los usuarios, los cuales establecieron sus preferencias hacia una reestructuración general de la visualización, que permita navegar en la aplicación de una forma más intuitiva, que sea amigable y a la vez responsiva, lo que permita el despliegue de la plataforma en múltiples dispositivos, para ello se utilizó el software Balsamic Muckups, y resultado de esto en la Figura 5 se observa el boceto de cómo el administrador general podrá visualizar los resultados estadísticos de los indicadores que se implantarán al sistema. 


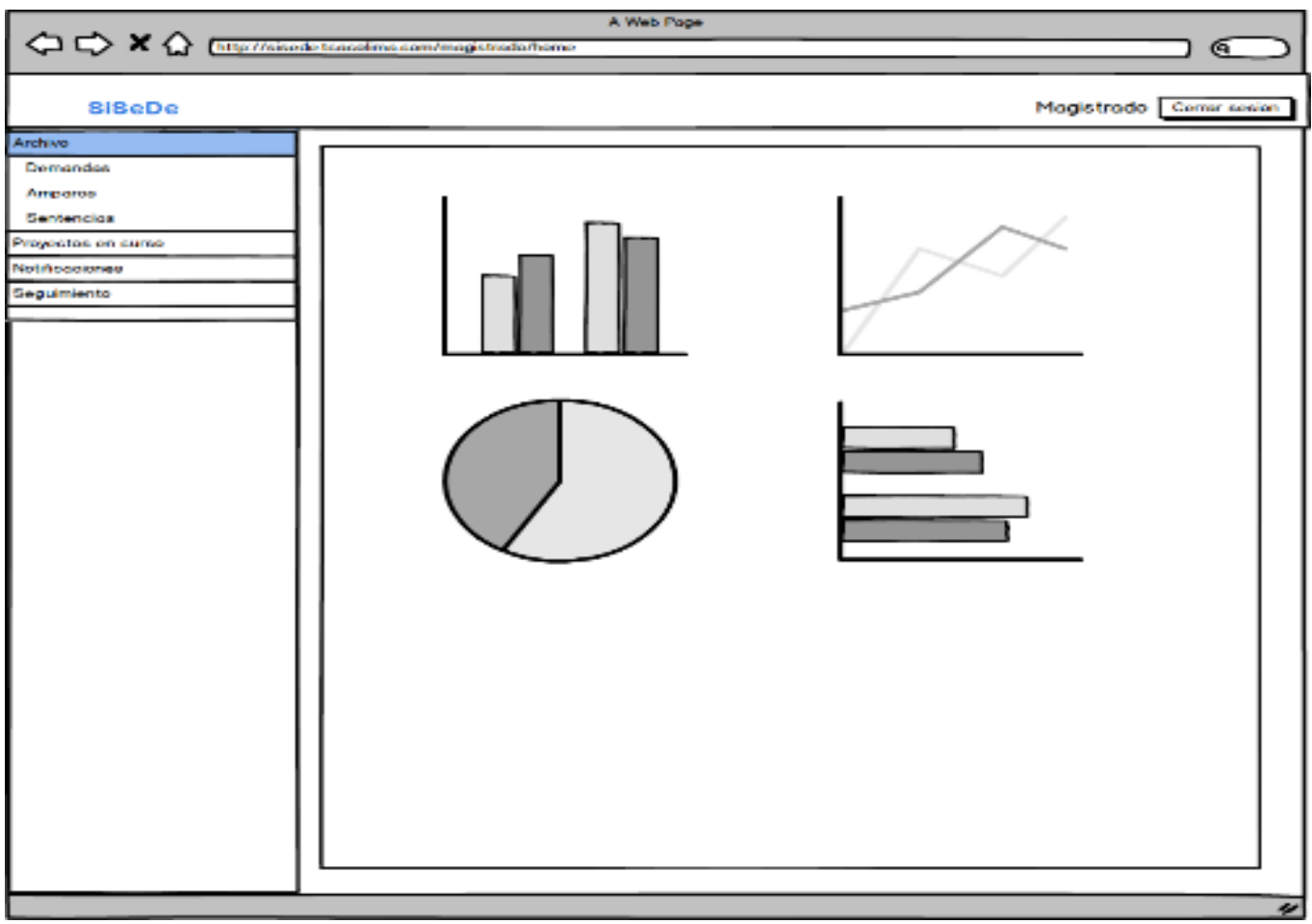

Figura 5. Boceto-Página de inicio del módulo de Administrador. Fuente: elaboración propia.

\subsection{REINGENIERÍA EN MODIFICACIÓN Y NUEVA FUNCIÓN DEL PROGRAMA}

La reingeniería aplicada al SiSeDe tuvo como alcance la modificación del producto con mejoras en el Registro de nuevas demandas como se muestra en la Figura 6, ahí el oficial de partes puede visualizar el histórico de las demandas, así como el monitoreo del estatus de cada una de los casos en revisión con la implementación de un semáforo de color, la cual indica mediante los colores verde, naranja y rojo, el estado que guarda la atención de la demanda. 


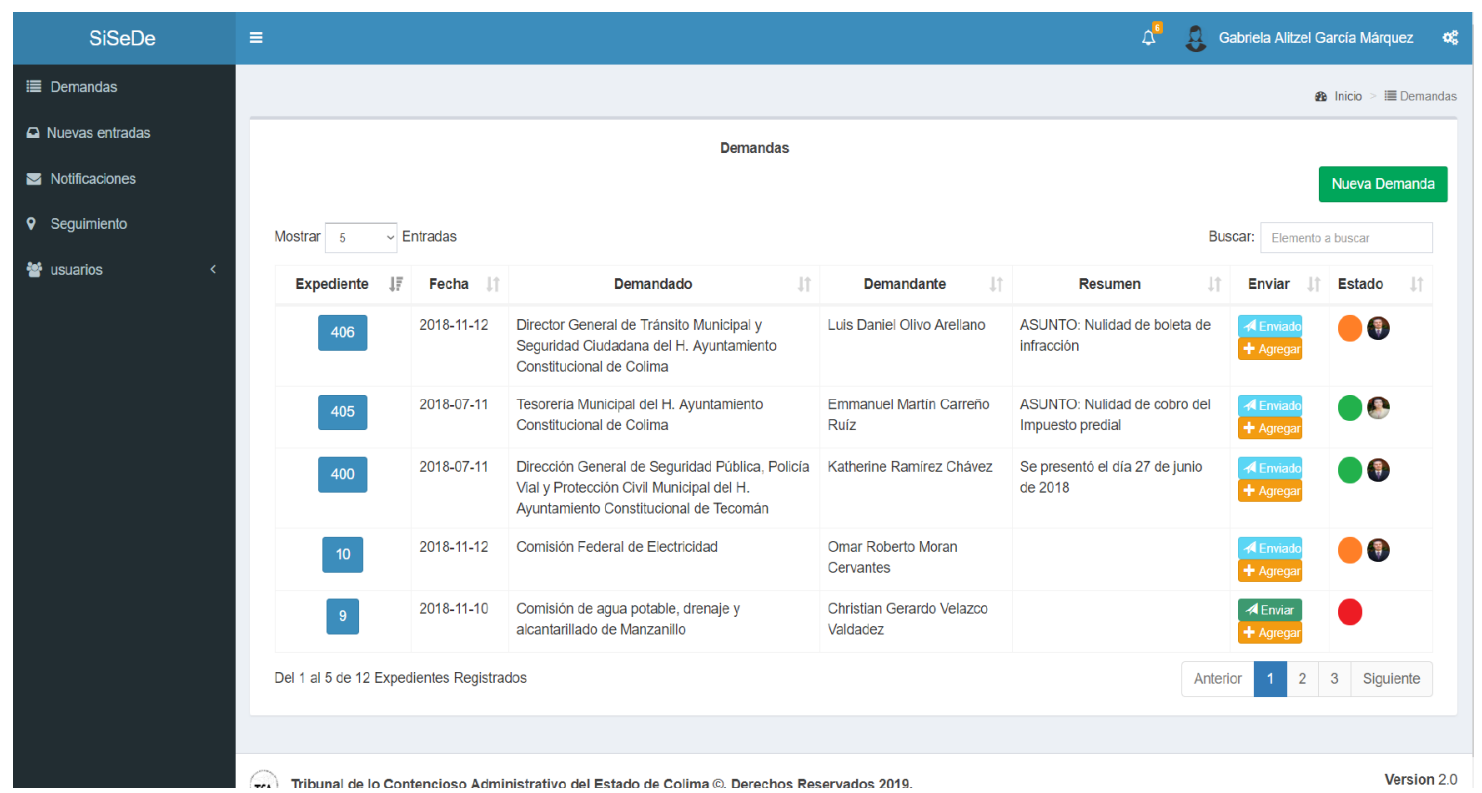

Figura 6. Página de Gestión de demandas del módulo de oficial de partes. Fuente: elaboración propia.

En la Figura 6 se pueden reconocer la nueva estructura para presentar la información al usuario, desde una perspectiva tabular, esto incluye datos como el número de expediente, la fecha de ingreso al sistema, lo participantes de la demanda, el resumen general y como anexo principal los indicadores de semáforo los cuales estipulan de forma visual el estado activo de la demanda, así como el personal que tiene en posesión dicho expediente. Los indicadores de color simbolizan respectivamente el tiempo de proceso para cada folio acorde a lo que establece la ley, teniendo marcadores verdes cuando se encuentra dentro de lo establecido, naranja cuando se exceda el tiempo recomendado y rojo cuando el proceso se encuentre en un periodo de desfase mayor al indicado en la ley.

En la Figura 7 se observa la forma en la que los magistrados visualizan la información estadística que generan los indicadores dentro del proceso de seguimiento de demanda, dentro de estas especificaciones, el administrador de sistema o magistrado puede elegir entre que visualizar: información por periodo de fecha, por expediente, tipo de expediente o tiempo de proceso de cada uno de los actores. 


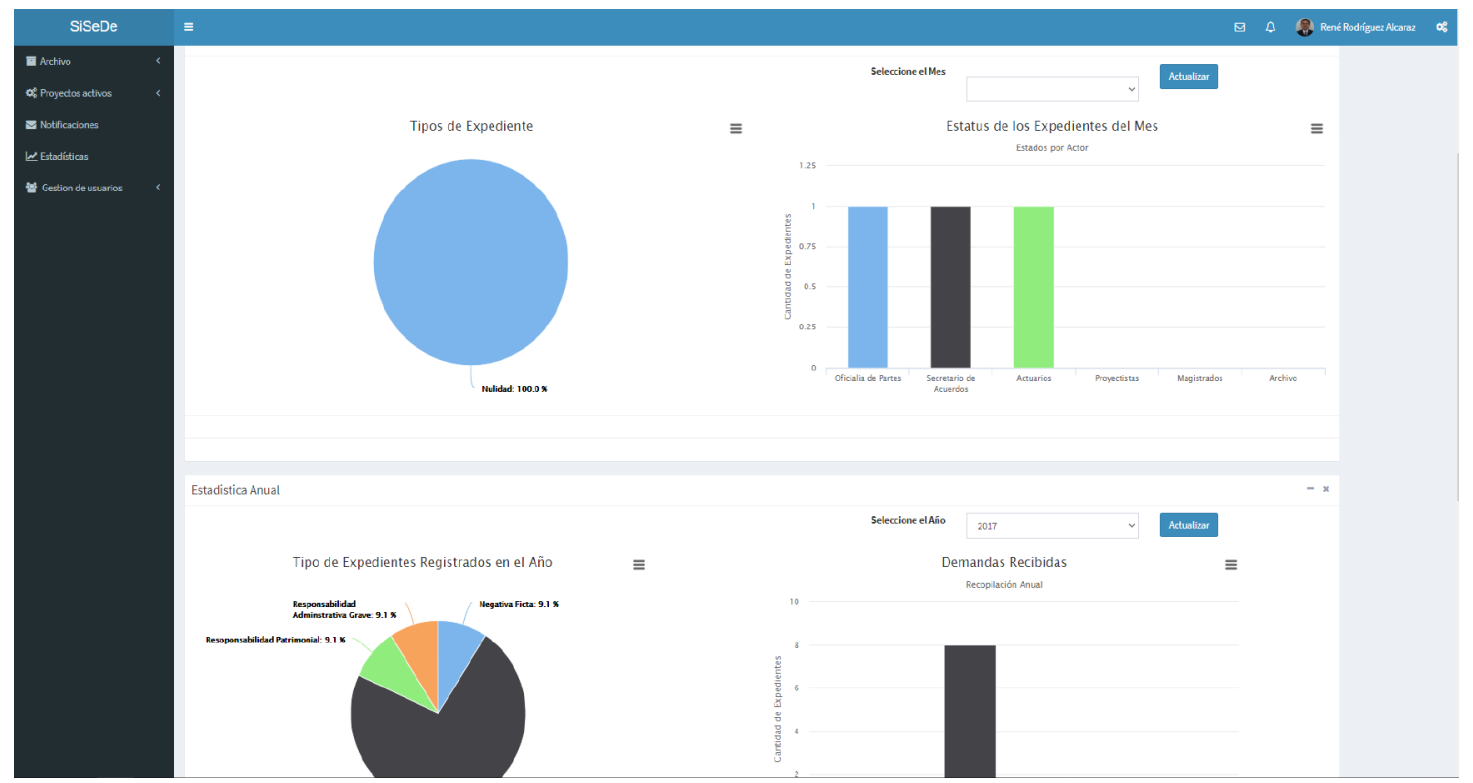

Figura 7. Página de inicio del módulo de Magistrados. Fuente: elaboración propia.

Un aspecto importante de la nueva funcionalidad es la integración del módulo de medición de productividad, para la cual se utilizaron tres indicadores de medición de tiempo, los cuales son: la métrica de rango DAU/MAU, ésta puede ser fácilmente modificable para medir la cantidad de casos únicos que interactúan en el sistema en un período de 30 días; la segunda métrica se encuentra definida en la Ley de Justicia Administrativa de Colima en sus artículos 52, 60, 64, 67, 71 y 91, que establecen las pautas de los tiempos que deberán de tomar los procesos de seguimiento de demanda, estableciendo los procesos de recepción, verificación de documentos, preparación de acuerdos para desechar o admitir el recurso de reclamación y la notificación de los mismos. Finalmente, se tomaron en cuenta aquellas especificaciones que los magistrados interpusieron para la evaluación de productividad de los actores.

En general la reingeniería estuvo enfocada en el módulo de indicadores de productividad, en la actualización del diseño de vistas para todos los usuarios y en la asignación de privilegios por perfiles de usuario; así el nuevo módulo permite dar seguimiento puntual a la atención de las demandas, y el diseño de vistas favoreció la usabilidad del sistema por parte de los actores. 


\subsection{PRUEBAS APLICADAS AL PRODUCTO}

Acorde a las especificaciones de prueba del sistema, que manejan algunos autores, estas se generalizan en dos. La primera, es cuando se conoce la función específica del diseño, a la cual se aplican pruebas que demuestren que cada función es plenamente operacional, además se buscan y localizan los posibles errores de la misma. La segunda es si se conoce el funcionamiento interno, esto produce pruebas en las que se asegura la correcta integración de cada módulo del sistema asegurando que se cumplan las especificaciones del mismo.

Para todo esto, con la ayuda de la herramienta PHPUnit se diseñaron e implementaron pruebas tanto unitarias enfocadas en acreditar el correcto funcionamiento de un módulo de código, clase o funcionalidad programada como se observa en la Figura 8, en donde se realiza la revisión de la clase que genera los correos electrónicos; en cambio cuando se requiere realizar una prueba de cómo funciona un conjunto de elementos unitarios para verificar que las partes del software funcionan correctamente, por ejemplo el evaluar los eventos de entrega de documento o avance dentro del proceso de seguimiento de la demanda como se observa en la Figura 9.

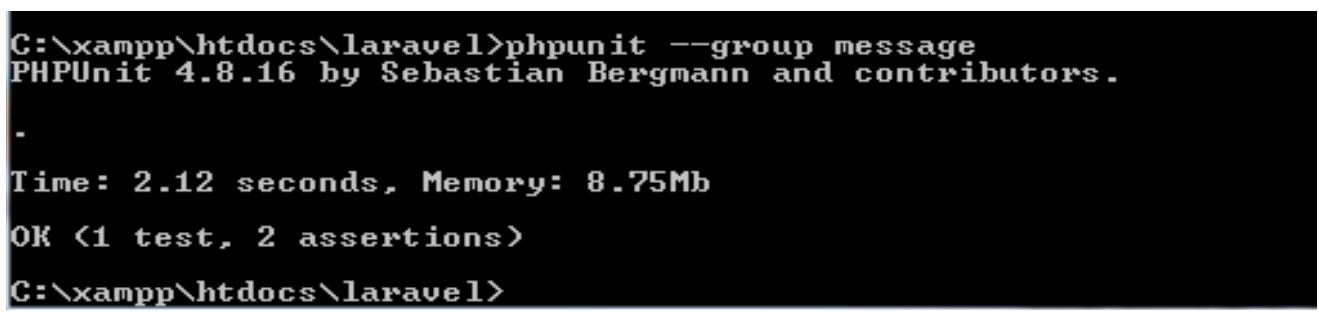

Figura 8. Ejemplo de prueba unitaria. Fuente: elaboración propia.

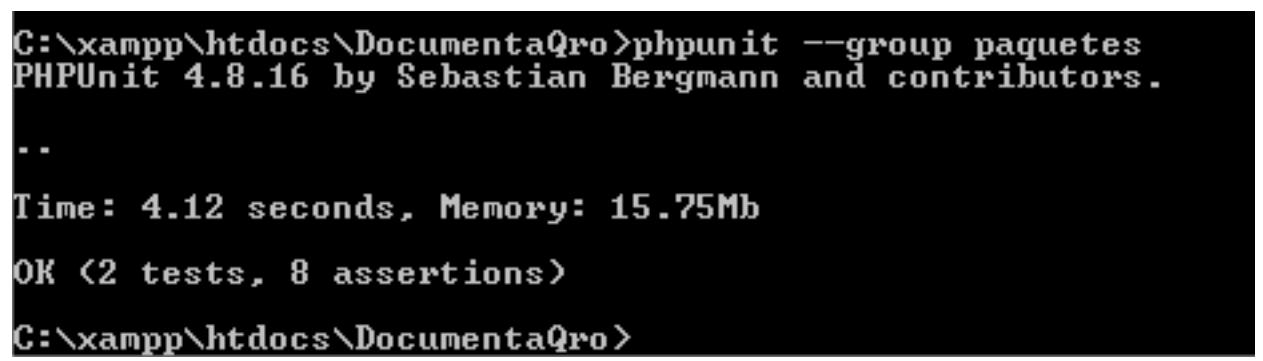

Figura 9. Ejemplo de prueba de integración. Fuente: elaboración propia. 
Dada la extensión del proyecto todas las pruebas unitarias y de integración se agruparon conforme a sus funcionalidades como se puede observar en la Tabla 1.

Tabla 1. Grupos de pruebas del sistema.

\begin{tabular}{|c|c|}
\hline Unitarias & Grupos de Pruebas \\
\hline Visualización de formularios & Escritura de información \\
\hline Visualización de menús & Subida de documentos \\
\hline Carga de vistas & Llenado de formularios \\
\hline Lectura de información & Validación de datos \\
\hline Generación de Correos de aviso & Envío de notificaciones \\
\hline
\end{tabular}

\section{CONCLUSIONES}

Con el presente desarrollo basado en la reingeniería del SiSeDe se cubrieron los nuevos requerimientos de la institución, se entrega una herramienta actualizada, desarrollada conforme lo establecido en las normativas de ley del TJA del Estado de Colima, México. Este sistema tiene la capacidad de dar atención integral al proceso de demanda, de manera interna al TJA, mientras se libera el juicio en línea. A diferencia de la primera versión del SiSeDe, este sistema otorga más funcionalidades que tienen que ver con el incremento de usuarios en un mismo rol, claro ejemplo de los magistrados; de igual manera, las funcionalidades de cada uno de los usuarios se vieron incrementadas, tanto para la gestión de sus labores dentro del proceso de seguimiento como para manejo y adaptación del sistema, entre estas la notificación automática vía correo electrónico y el envío del expediente electrónico entre los actores que atienden el proceso de la demanda. Por otro lado, la base de datos original, después de aplicar procesos de normalización, se redujo de 25 tablas a 19, permitiendo que los aspectos de eficiencia, flexibilidad de almacenamiento, recuperación ante errores, así como el escalamiento de alcances del sistema en un futuro inmediato se vean incrementados.

Respecto a la visualización e interfaces de usuario, todas las vistas del sistema se ampliaron y modificaron, tomando en consideración un enfoque minimalista y usable, lo que permite al usuario tenga en primer 
plano toda la información prioritaria y con un fácil acceso, gracias a la integración de paneles de navegación, notificaciones y alertas que retroalimentan al usuario sobre sus acciones en el sistema.

Para el desarrollo de este sistema se planteó la hipótesis que establece que el seguimiento informático a los indicadores de productividad establecidos, permite a la organización realizar evaluaciones periódicas de la eficiencia de sus procesos para mantener la mejora continua de la misma; dicha hipótesis aún se encuentra en proceso de validación, debido que el software se encuentra en su etapa de liberación.

La hipótesis permite a la organización realizar evaluaciones periódicas de la eficiencia de sus procesos para mantener la mejora continua de la misma.

\section{Recomendaciones y puntos de mejora}

Unos de los puntos de mejora será la necesidad de desarrollar e implementar un sello o firma digital a cada uno de los documentos que conforman los expedientes, esto aumentará el nivel de seguridad de los mismos y además integrarán un respaldo legal, representando una medida de legalidad y legitimidad en cada uno de los documentos. También será importante incorporar los audios de las reuniones del pleno, a fin de mantenerlas en un repositorio propio del SiSeDe. Pese a que se tiene la infraestructura en esta reingeniería del SiSeDe, queda pendiente la habilitación del juicio en línea, porque está sujeto a la liberación de la ley que lo declare válido; una vez habilitado el juicio en línea podría difundirse en redes sociales, para que los usuarios demandantes tengan presente el medio donde puedan colocar sus demandas. 


\section{REFERENCIAS BIBLIOGRÁFICAS}

Ambler, S. W. (2014). The Agile Unified Process. Recuperado de: http://www.ambysoft.com/ unifiedprocess/agileUP.html

Balsamiq Studios, LLG. (2018). Balsamiq Muckups. Recuperado de: https://balsamiq.com/products/

Bergmann, S. (2018). PHPUnit. Recuperado de: https://phpunit.de/index.html

Fernández, J. M., y Moreno, A. A. (2017). Diseño e Implementacion de un sistema de informacion para el seguimiento de proyectos de sentencias en el tribunal de lo contencioso administrativo. $3 C$ TIC, 6(2), pp. 1-27. doi: http://dx.doi.org/10.17993/3ctic.2017.56.13-27

GEGKOBOARD. (2017). DAU/MAU ratio. Recuperado de: https://www.geckoboard.com/learn/kpiexamples/startup-kpis/dau-mau-ratio/\#.WiZBl0qWbIU

H. Congreso del Estado de Colima. (16 de junio de 2018). Ley de lo Contencioso y Administrativo del Estdo de Colima. Recuperado de: Última Reforma Decreto 133: http://congresocol.gob.mx/web/ Sistema/uploads/LegislacionEstatal/LeyesEstatales/Justicia_Administrativa_16jun2018.pdf

Jürgen, E., Franz, L., Volker, R., y Andreas, W. (2005). Informatik - Forschung und Entwicklung, 19(3), pp. 125-126. doi: https://doi.org/10.1007/s00450-005-0183-y

March, J., y Sutton, R. (1997). Organizational Performance as Dependet Variable. Organization Science, pp. 698-706. Recuperado de: https://pubsonline.informs.org/doi/pdf/10.1287/orsc.8.6.698

Mejía, G. A. (2007). Seguimiento de la Productividad en Obra: Técnicas de Medición de Rendimientos de Mano de Obra. UIS Ingenierías, 6(2), pp. 45-59. Recuperado de: http://search.ebscohost.com/ login.aspx?direct=true\&db=zbh\&AN=36074334\&site=ehost-live

Microsoft. (2018). Extract, transform, and load (ETL). Recuperado de: Microsoft Azure: https://docs. microsoft.com/en-us/azure/architecture/data-guide/relational-data/etl 
3C Tecnología. Glosas de innovación aplicadas a la pyme. ISSN: 2254-4143

Olsem, M. R., Sittenauer, G., Dawood, M., y Rasmussen, K. J. (1995). Reingineering Technology Report, 2. UTHA: Defense Technical Information Center. Recuperado de: http://www.dtic.mil/ $\mathrm{dtic/tr/fulltext/u2/a324750.pdf}$

Sicilia, M. A., y De la Morena, V. (2009). Técnicas de mantenimiento de Software. Huston, Texas: Rice University. Recuperado de: https://cnx.org/contents/RunP_m1t@6.1:jXj8TA20@3/Qu-esReingeniera-del-Software

Sommerville, I. (2005). Ingeniería de Software. Ámsterdam: Pearson Education.

Talend. (2018). Open Source Integration Software. Recuperado de: Talend Open Studio: https://www. talend.com/products/talend-open-studio/

Workmeter. (12 de junio de 2012). Indicadores de productividad, ¿Qué son y cómo analizarlos? Recuperado de: El blog de WorkMeter; Consejos para hacer crecer tu negocio: https://es.workmeter.com/blog/ bid/172634/indicadores-de-productividad-qu-son-y-c-mo-analizarlos

34 । 


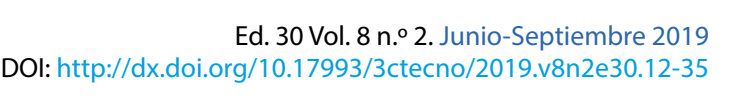


/02/ 


\title{
BLOCKCHAIN VS ISO 9001:2015 BLOCKCHAIN VS ISO 9001:2015
}

\author{
Víctor Gisbert Soler \\ Doctor Ingeniero Industrial. \\ Profesor Universitat Politècnica de València. \\ E-mail: vgisber@eio.upv.es
}

Ana Isabel Pérez Molina Doctora en Ingeniería en Organización Industrial. Profesora Universitat Politècnica de València.

E-mail: anpemo@eio.upv.es

\section{Gitación sugerida:}

Gisbert Soler, V. y Pérez Molina, A. I. (2019). Blockchain vs ISO 9001:2015. 3C Tecnología. Glosas de innovación aplicadas a la pyme, 8(2), pp. 36-49. doi: http://dx.doi.org/10.17993/3ctecno/2019.v8n2e30.36-49 


\section{RESUMEN}

En la presente comunicación se realiza una pormenorizada introducción sobre la tecnología Blockchain, los beneficios de su utilización, así como su utilización en los llamados contratos inteligentes.

Se desarrolla de forma detallada las posibles aplicaciones de Blockchain ligadas a un sistema de gestión de la calidad basado en la norma ISO 9001:2015.

Se realiza un estudio sobre las principales características principales del uso, funciones clave en los términos de fabricación en general, y en gestión de la calidad, para concluir sobre diferentes casos de uso de fabricación avanzada y gestión de aprovisionamientos.

\section{PALABRAS CLAVE}

Blockchain, ISO 9001, Contratos inteligentes.

\section{ABSTRACT}

In the present communication a detailed introduction is made about the Blockchain technology, the benefits of its use, as well as its use in the so-called intelligent contracts.

The possible Blockchain applications linked to a quality management system based on ISO 9001: 2015 are developed in detail.

A study is made on the main characteristics of the use, key functions in the terms of manufacturing in general, and in quality management, to conclude on different cases of use of advanced manufacturing and procurement management.

\section{KEYWORDS}

Blockchain, ISO 9001, Intelligent contracts. 


\section{INTRODUCCIÓN}

Blockchain se asocia comúnmente con la transferencia de activos digitales. Se trata esencialmente de bloques de código de programación que están vinculados entre sí de manera segura.

De esta forma, un blockchain puede entregar un registro inmutable e irreversible para activos digitales y puede tener innumerables aplicaciones prácticas tanto en fabricación como en aseguramiento y control de calidad.

En este artículo se analizan las aspiraciones digitales en aseguramiento y control de calidad y como podría mejorarse mediante la aplicación de blockchains.

El principal hallazgo y conclusiones es que blockchain se puede utilizar para proporcionar herramientas avanzadas para la gestión de la calidad, con verificación de propiedad segura, piezas, validación de pedidos, inspecciones realizadas, controles de proceso, etc.

Podemos concluir que las aplicaciones de blockchain pueden ofrecer un método robusto y resistente de la indexación del historial de registros que se puede distribuir y almacenar en Internet. Esta capacidad de indexación lo hace especialmente útil en gestión de la calidad, como posteriormente veremos.

El blockchain ayuda en la identificación y por lo tanto la eliminación de la falsificación. También como resultado de la digitalización y propiedades de los registros, blockchain tiene muchas otras aplicaciones potenciales, ya que su uso agrega rigor a la medición y trazabilidad que se requiere en la fabricación. También puede facilitar la personalización exigida en cualquier fabricación, pudiéndose utilizar para rastrear tanto el "uso" como el "efecto" en la cadena de suministro.

Blockchain tiene muchas aplicaciones potenciales, ya que su uso agrega rigor a la medición y trazabilidad que se requiere en la fabricación.

$\mathrm{Al}$ igual que en las aplicaciones financieras, los fabricantes pueden utilizar blockchain para ver el estado de los pagos, facturas, documentos y datos digitalizados, se puede utilizar para dar una visibilidad detallada del producto a través de toda la cadena de suministro, la cual se ve reforzada por capacidad de blockchain para almacenar y procesar todos los registros y datos inherentes a esa producción. 
$\mathrm{Al}$ no poder ninguna parte modificar o eliminar ningún registro sin consenso, el nivel de transparencia proporcionado por blockchain, además de facilitar la trazabilidad, puede ayudar a reducir el fraude y los errores.

También podría ayudar a reducir el tiempo en los productos están tanto en producción como en almacenamiento y distribución, al mejorar la gestión de inventario y reduciendo tiempos muertos y desperdicios.

Este documento propone casos avanzados de uso de fabricación y gestión de la calidad para ilustrar el potencial de Blockchain.

En primer lugar, Blockchain nos puede servir para ver el estado de los bienes a través de la cadena de valor. Esto a su vez arroja visibilidad sobre donde los componentes están en el proceso de valor agregado.

En segundo lugar, Blockchain puede ayudarnos para el análisis de series de tiempo. En gestión de la calidad, las series de tiempo se utilizan en el control del producto y prestación del servicio.

Las variables monitoreadas son activos digitales, que incluyen, por ejemplo, cualquier variable que quiera ser controlada, como unos diámetros de componentes de precisión, o atributos, características de calidad que no pueden ser revisadas mediante una escala de medida, tanto en materia prima, producto en proceso y terminado.

Los gráficos de control incluyen series de tiempo con límites superiores e inferiores de control, que como hemos dicho pueden ser variables de proceso u otro tipo de indicadores de eficiencia de proceso, kpi's, como tiempo que lleva procesar un pedido, cambio rápido de formato, materia prima utilizada, resultado de una inspección por muestreo, etc.

\section{LOS BENEFICIOS DE USAR BLOCKCHAIN}

Blockchain es una tecnología habilitadora que puede ayudar a reducir la carga manual del cumplimiento y procesos de control e inspección (2 Deloitte).

Es válido donde quiera que haya relaciones basadas en la confianza en el suministro, que deba ser transparente o verificado por un tercero mientras se mantiene confidencialidad y / o intermediación. 
Un ejemplo es una empresa que busca obtener un servicio de logística donde el envío, por ejemplo, de alimentos congelados, la temperatura nunca deba ser superior a cero centígrados. Esto puede ser verificado automáticamente a través de Ia tecnología Blockchain.

Así pues, Blockchain puede ayudar a la selección de proveedores en base a hechos constatables, en lugar del habitual procedimiento de evaluación de proveedores basado en garantías o auditorías de cumplimiento.

La potencialidad de Blockchain permitirá mejorar el valor de los productos adquiridos a subcontratistas al existir plena transparencia en su realización.

\section{CONTRATOS INTELIGENTES}

Se ha prestado considerable atención al potencial de la tecnología blockchain para ser utilizada en contratos inteligentes. Un contrato inteligente es esencialmente un acuerdo escrito en código de programación y entregado por un blockchain (2 Ethereum).

$\mathrm{Al}$ igual que el blockchain financiero, en el que una parte tiene posesión de un artículo y puede privar a otro de parte de acceso a la propiedad, se puede proceder de igual manera en gestión de la calidad.

En estos casos, el contrato inteligente sirve como una prueba de acuerdo firmado criptográficamente entre las dos partes. Desde una perspectiva tecnológica, los contratos inteligentes a menudo se ven como fuera de la jurisdicción convencional, pero desde una perspectiva legal, existe el derecho de acceso a la justicia ordinaria.

El proceso de permitir que un tribunal se pronuncie sobre un contrato inteligente, donde los términos no pueden ser alterados presenta un desafio significativo para futuras investigaciones.

Desde una perspectiva tecnológica, los contratos inteligentes a menudo se ven como fuera de la jurisdicción convencional, pero desde una perspectiva legal, existe el derecho de acceso a la justicia ordinaria. 


\section{APLICACIONES DE GESTIÓN DE LA CALIDAD EXISTENTES PARA BLOCKCHAIN}

En esta sección exploramos los usos de blockchain que ya se han implementado en la gestión de la calidad (3 Cointelegraph).

Algunos ya están disponibles en el mercado en este momento, otros se han propuesto, pero aún no se han implementado.

\section{Procedencia del producto al por menor}

Hay una serie de productos y servicios en el mercado de hoy cuyo valor está ligado, en mayor o menor grado, a su 'procedencia', como por ejemplo productos alimenticios producidos de manera sostenible, artículos de lujo, etc.

La tecnología Blockchain se puede usar para establecer la procedencia de productos manufacturados avanzados. En la actualidad hay varias empresas que ya operan en el contexto de la tecnología blockchain para determinar la procedencia.

Dichas empresas se centran en la responsabilidad de la cadena de suministro de los productos, trabajan con proveedores para recopilar información del proceso de la cadena de suministro y compartir esta información con los clientes en el punto de venta del producto.

Usando este enfoque, blockchain se puede usar para rastrear materiales y productos, y funciona a nivel de artículo. Proporciona una experiencia orientada al cliente, que detalla los pasos clave en la producción de un producto.

La cadena de suministro se modela como compuesta por productores, fabricantes, registradores, organizaciones de estándares, certificadores y auditores, y clientes.

Los registradores actúan como gestores de confianza para verificar la identidad y las credenciales de los otros participantes nombrados. Las organizaciones de estándares definen requisitos para una aprobación dada (por ejemplo, no pruebas con animales en productos farmacéuticos), y las organizaciones permiten que se agreguen lotes de productos a este grupo. El proceso de aprobación de un fabricante para un 
estándar dado puede requerir una certificación o auditoría, que se llevaría a cabo por un auditor. Una verificación exitosa da como resultado un fabricante que está registrado en una entidad de certificación.

Después de la certificación, un productor tiene un programa de producción aprobado, que está certificado para una capacidad de producción determinada durante un período de tiempo.

\section{$\underline{\text { Transparencia en la cadena de suministro }}$}

Cada vez más los fabricantes quieren que la procedencia de los productos esté más disponible para el usuario final.

Como se señaló en la introducción, la gestión de la calidad proporciona una mayor cantidad de valor para el cliente a través de sus actividades. Esto se logra mediante el despliegue de altos niveles de tecnología, habilidad y conocimiento.

En una cadena de suministro tradicional, esto es aceptado por el cliente basado en la confianza de las distintas certificaciones, que han llevado a algunos escándalos en los últimos años por la no validez o manipulación de esas certificaciones.

El uso de blockchain proporciona una manera de abordar esta brecha entre confianza percibida y comportamiento real. Por ejemplo, un índice de las partes involucradas en la producción de un producto se puede registrar de forma indeleble en blockchain del producto.

Esta capacidad puede extenderse para proporcionar alguna evidencia que respalde cualquier reclamación hecha sobre productos o servicios previstos.

\section{$\underline{\text { Historial de servicio rastreable }}$}

El uso de registros de la actividad de servicio habilitados por blockchain en un activo que ya ha sido identificado como posible uso por parte de empresas fabricantes. En la larga vida de un vehículo comercial, el historial de servicio y las piezas usadas se convierten en un patrón complejo de uso o actividad, mantenimiento y reemplazo de piezas. Con las tecnologías actuales esto requiere disciplina para mantener y no es difícil de falsificar. 
Las soluciones Blockchain ayudan siendo esencialmente automatizadas. Es cierto que las partes interesadas todavía tienen para acordar el uso de la cadena de bloques, pero mantiene un índice inalterable de eventos en el que la secuencia se mantiene. Esto apoyará una evaluación sostenida en información veraz de los valores de los activos a lo largo de su vida.

Fabricación habilitada para IoT

Internet de las cosas (IoT) es una tendencia tecnológica en desarrollo que ha sido ampliamente predicha y aún no se ha implementado.

La aplicación de IoT dentro de la fabricación es un paso natural y hoy existen varios ejemplos de aplicaciones basadas la interacción con la maquinaria de producción. Un ejemplo típico es una máquina $\mathrm{CNC}$ de mensajes de texto al operario cuando se requiere soporte para un próximo cambio de herramientas. Se puede considerar parte de la próxima generación de evolución de la industria (industria 4.0).

La aplicación de loT dentro de la fabricación se puede considerar parte de la próxima generación de evolución de la industria (industria 4.0).

Blockchain ha sido identificada como tecnología de apoyo, proponiéndose una plataforma de uso general para el uso de blockchain en el IoT industrial que permite la fabricación "bajo demanda".

Esto ha sido descrito de diversas maneras como fabricación en nube y fabricación distribuida, y se considera que ofrece importantes flexibilidad y ventajas de costo sobre la fabricación típica.

\section{CARACTERÍSTICAS PRINCIPALES DEL USO}

Funciones clave en los términos de fabricación en general, y en gestión de la calidad en particular, son 5 (Ferrer, 2018):

- Resistencia a la manipulación. La naturaleza distribuida de la base de datos hace que sea muy difícil cambiar registros de transacciones pasadas. 
- Trazabilidad incorporada. Un corolario de la resistencia a la manipulación es que la trazabilidad de las transacciones puede ser incorporada a la cadena de bloques. Cada transacción se registra y no se puede modificar en la práctica, existiendo un rastro de tales transacciones.

- Transparencia en lugar de confianza. Sobre la base de las dos características anteriores, la cadena de bloques puede ser visto como una historia transparente de lo que ha sucedido. Esta transparencia puede ser lograda a través del uso de claves criptográficas.

\section{CASOS DE USO DE FABRICACIÓN AVANZADA Y GESTIÓN DE APROVISIONAMIENTOS}

\section{Economía circular / refabricación}

El término "economía circular" implica el movimiento desde la extracción de las materias primas, su posterior conformado para convertirla en productos que luego son utilizados y posteriormente eliminados una vez se cierra el ciclo.

La refabricación ofrece el potencial de reducir en gran medida la utilización de recursos, al tiempo que proporciona la función y garantías de nuevos productos. Es una industria en claro crecimiento como son los casos de los sectores del automóvil, electrónica, sector aeroespacial, etc.

Dentro de la refabricación nos podemos encontrar:

- Remanufactura: devuelve al producto usado una nueva especificación de rendimiento y le da al producto resultante una garantía que es al menos igual a la de un producto nuevo equivalente.

- El reacondicionamiento: devuelve un producto a unas condiciones de funcionamiento satisfactorias que pueden ser inferiores a la especificación original y a da una garantía menor que la de nueva fabricación de producto.

- La reparación corrige las fallas especificadas en un producto y da una garantía menor al nuevo producto manufacturado que puede no cubrir todo el producto. 
- El reciclaje: recupera materiales para el propósito original o un nuevo propósito.

El factor clave de éxito en cualquier cadena de refabricación es la condición y el estado de los productos devueltos, que aumentará el valor al tener pleno conocimiento y, por tanto confianza, en que los artículos devueltos son correctos, al incorporar:

- Un registro de la especificación del producto devuelto que es inmutable y preciso.

- Más información transparente sobre el estado del producto devuelto.

- Claridad del estado del producto devuelto después de la remanufactura.

\section{$\underline{\text { Servicios de ingeniería de por vida }}$}

Productos complejos, por ejemplo, barcos, ferrocarriles, centrales eléctricas, etc. se caracterizan por ciclos de vida operacionales durante los cuales los sistemas que componen el producto pueden necesitar ser modificados, reparados o reemplazados.

Actualmente la gestión del producto, la configuración y los datos relacionados se realizan a través de registros y auditorías que confirman la trazabilidad y confianza en las operaciones. Estas operaciones suelen ser procesos sofisticados para mantener y administrar, y a menudo necesitan ser restringidos en el alcance para ser prácticos.

Usos actuales propuestos de blockchain podrían mantener la información del producto de una manera que sea independiente, actualizada y veraz.

\section{$\underline{\text { Sistemas de servicio del producto }}$}

Existe una tendencia creciente a ofrecer productos como servicio en lugar de venderlos a los clientes. Estas proposiciones comerciales tienen su propia lógica y no requieren una distribución.

Sin embargo, el uso de blockchains ofrece un cierto potencial de beneficios para los sistemas de servicio del producto, como son la ampliación de los sistemas de servicio de productos a mercados más amplios y la capacidad de desintermediación que elimina la función de corretaje en un mercado. 


\section{CONCLUSIONES}

La principal la conclusión es que blockchain ofrece ventajas significativas para la gestión de la calidad.

Las oportunidades que identificamos provienen de factores de reducción de costos, auditorías, validaciones y controles sobre el producto. Todo eso sin tener en cuenta otras ventajas como son una mayor capacidad de respuesta, valor agregado en el producto final y nuevos servicios basados en la información de blockchain.

Por eso entendemos que Blockchain es perfectamente compatible con la gestión de la calidad con el fin de lograr el máximo beneficio. Entendemos que en las etapas intermedias pueden ser mejoradas y "conectadas" a través de interfaces blockchain en sistemas de gestión de la producción, tipo ERP, a nivel corporativo.

También encontramos un gran beneficio para evitar la falsificación y copia al usar esta tecnología, reduciendo de forma importante el valor de las copias 'clonadas'.

A corto plazo los beneficios se centran en la autentificación de cadena de suministro, mientras que a largo plazo están más relacionados con el ciclo de vida del producto. 


\section{REFERENCIAS BIBLIOGRÁFICAS}

Ferrer, A. (2018). Aplicación del blockchain a los datos. Recuperado de: https://es.slideshare.net/maredata/ antonia-ferrer-aplicacin-del-blockchain-a-los-datos

Rodríguez Roldán, D. (s.f.). Blockchain: cambiando los modelos de relacióny confianza. Recuperado de: https:// www2.deloitte.com/es/es/pages/governance-risk-and-compliance/articles/blockchain-cambiandomodelos-relacion-confianza.html

Rojas, E. (2019). ¿Qué son los contratos inteligentes o «smart contracts?? Guía completa. Recuperado de: https:// es.cointelegraph.com/explained/what-is-a-smart-contract 


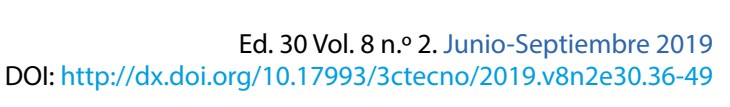


/03/ 


\title{
IMPORTANCIA DEL MANTENIMIENTO, APLICACIÓN A UNA INDUSTRIA TEXTIL Y SU EVOLUCIÓN EN EFICIENCIA IMPORTANCE OF MAINTENANCE, APPLICATION TO A TEXTILE INDUSTRY AND ITS EVOLUTION IN EFFICIENCY
}

\author{
Julio García Sierra \\ Estudiante Posgrado, Instituto Politécnico Nacional, México. \\ E-mail: sierracien10@gmail.com
}

Javier Cárcel Garrasco

Profesor, Universitat Politècnica de València, España.

E-mail: fracarc1@csa.upv.es ORCID: https://orcid.org/0000-0003-2776-533X

Juvenal Mendoza Valencia

Profesor, Instituto Politécnico Nacional, México.

E-mail: juvenalmv69@gmail.com

Recepción: 17/04/19 Aceptación: 11/06/19 Publicación: 14/06/19

Gitación sugerida:

García Sierra,J., Cárcel Carrasco,J. y Mendoza Valencia,J. (2019). Importancia del mantenimiento, aplicación a una industria textil y su evolución en eficiencia. 3C Tecnología. Glosas de innovación aplicadas a la pyme, 8(2), pp. 50-67. doi: http://dx.doi.org/10.17993/3ctecno/2019.v8n2e30.50-67 


\section{RESUMEN}

La importancia hoy en día del mantenimiento por su contribución a la productividad es innegable. Este artículo expone un análisis de la evolución del mantenimiento, en referencia a una fábrica de tejido, haciendo una descripción por medio de sus datos reales, se propone una reestructuración del método de mantenimiento, que evidentemente si se implementara se obtendrían mejoras en la productividad. El tema es complejo por naturaleza ya que, según los métodos actuales de mantenimiento, debe ser abordado desde diferentes ángulos (multidisciplinar) y en todos los niveles de la organización por ser una actividad Logística de nivel estratégico.

\section{PALABRAS CLAVE}

Mantenimiento, Gestión de activos, Fiabilidad, Disponibilidad, Seguridad.

\section{ABSTRACT}

The importance today of maintenance for its contribution to productivity is undeniable. This article presents an analysis of the evolution of maintenance, in reference to a fabric factory, making a description by means of its real data, a restructuring of the maintenance method is proposed, which evidently, if implemented, would result in improvements in productivity. The subject is complex by nature since, according to current methods of maintenance, it must be approached from different angles (multidisciplinary) and at all levels of the organization because it is a Logistics activity at a strategic level.

\section{KEYWORDS}

Maintenance, Asset management, Reliability, Availability, Security. 


\section{INTRODUCCIÓN}

Gracias a los avances del conocimiento en las ciencias físicas, los siglos XVII y XVIII son un punto de inflexión en la evolución de los avances tecnológicos en la historia de la humanidad, pues se desarrollaron diversos ingenios capaces de aprovechar la energía para producir bienes o servicios, al desarrollar máquinas que funcionan con electricidad, vapor o principios mecánicos, trayendo como consecuencia que la forma de producción de esos satisfactores, se concentraran en instalaciones especiales llamadas fábricas, para cumplir sus objetivos.

Si hacemos una comparación de la forma de producir productos o servicios de la prehistoria al siglo XVIII se puede decir que existe una gran diferencia, y a su vez si comparamos la forma de producir de este último a la actualidad, obtendremos una diferencia aún mayor en tan poco tiempo, en el sentido de que actualmente se nota una mejor calidad de vida, pero una mayor producción de satisfactores para cubrir las necesidades actuales.

Por lo tanto, enfocándonos observamos que el tema de mantenimiento siempre ha existido y es paralelo a esta evolución; pues se le proporcionó mantenimiento a una herramienta, después a la maquinaría y ahora a los equipos industriales, tratando de conservar siempre al activo, o mejor aún alargar su vida útil. Consecuentemente la necesidad de contar con conocimientos para mantenimiento en las diversas disciplinas está condicionada al avance de la ciencia y la tecnología que se transforma en desarrollos tecnológicos que hoy tenemos. Estas máquinas, desarrollos o equipos, obedecen a los principios físicos con los cuales trabajan, siendo el conocimiento base relevante, para proporcionar el mantenimiento (Cárcel, 2014).

La necesidad de contar con conocimientos para mantenimiento en las diversas disciplinas está condicionada al avance de la ciencia y la tecnología que se transforma en desarrollos tecnológicos que hoy tenemos.

Actualmente, se demuestra que el papel del mantenimiento en una organización es destacado por que garantiza aportaciones a la productividad, por medio de la confiabilidad y disponibilidad de los equipos, maquinaría e instalaciones, impactando también en la calidad, seguridad y salud en todos sus aspectos (Rojas, 2008). 
Puntualizando y para tener una idea de su evolución en nuestro objeto de estudio, a manera de referencia histórica, la fábrica de tejido se ubica dentro de un complejo de fábricas que inició actividades productivas en 1917 integrándose por algunos talleres, plantas y servicios, pasando por diferentes denominaciones y capacidades ya que la producción fue en aumento con el paso del tiempo. Por cuestiones de confidencialidad se omite el nombre.

En 1986, se realizó una reorganización y remodelación de todo el complejo, invirtiéndose también en maquinaria y equipo, reemplazando los equipos obsoletos, se implementaron nuevos sistemas productivos para cumplir con eficiencia los programas de producción; notándose la integración de personal altamente capacitado.

Como concepto global, sin perder de vista el aspecto de mantenimiento en esta evolución, el complejo está organizado en una dirección, una subdirección y las jefaturas de producción, ingeniería, mantenimiento, administrativa y desarrollo. La jefatura de producción materializa la fabricación de los productos en 11 plantas productivas. Una de esas plantas es la fábrica de tejido, de esta fábrica se obtuvieron los datos como un termómetro que indicará la situación, para opinar sobre la mejora de su método de mantenimiento. Esta fábrica de tejido produce diversos tipos de telas; Con el fin de seguir cumpliendo su objetivo, en el año 2015 se reemplazaron "30 telares neumáticos” y una maquina engomadora.

Otra jefatura importante de las citadas en referencia al tema es la jefatura de mantenimiento, pues su misión es proporcionar mantenimiento preventivo y correctivo a la maquinaria de todo el complejo, instalaciones industriales e inmuebles. Al respecto se observa que orgánicamente esta jefatura está al mismo nivel que las demás jefaturas como producción y administrativa (Tavares, 2014), además, de acuerdo con el manual de organización y operación interior, a esta jefatura le corresponde efectuar trabajos de tercer nivel con equipos móviles y personal especializado que no tienen las demás fábricas como la de tejido en estudio, a quienes localmente les corresponde el mantenimiento de segundo nivel que son actividades tales como el reemplazo de refacciones y actividades de mantenimiento preventivo. El primer nivel le corresponde al operario de la máquina, haciendo adecuado uso, limpieza y lubricación de la máquina y cambio de partes autorizadas por su siguiente nivel, entre otras actividades menores. 
La fábrica de tejido plano es pues, una de las once fábricas que componen el complejo de Fábricas remodelada en 1993; esta planta de tejido cuenta con un programa de producción anual de tela y es aquí a donde se hace este estudio

\section{CARACTERÍSTICAS DE LA FÁBRICA TEXTIL}

Para observar la importancia que el mantenimiento tiene en este tipo de industria, es importante conocer las características de su personal y de su producción. La fábrica de Tejido tiene una plantilla de total 78 personas, distribuidas en tres turnos, ocupando una jefatura y seis áreas que son: el grupo de administrativo, almacén, urdido, engomado, tejido y mantenimiento local.

El proceso de producción de tela en la fábrica de tejido plano la realiza en carretes de aluminio denominados "julio" el cual mide $2 \mathrm{~m}$ de ancho este carrete está presente en las tres operaciones básicas como se muestra en la (Figura 1).

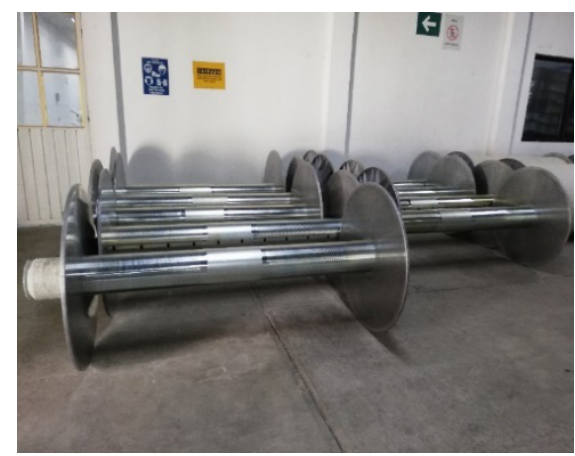

Figura 1. Carrete de aluminio denominado “Julio". Fuente: elaboración propia.

La Figura 2 muestra las tres operaciones básicas para el proceso de elaboración de la tela.

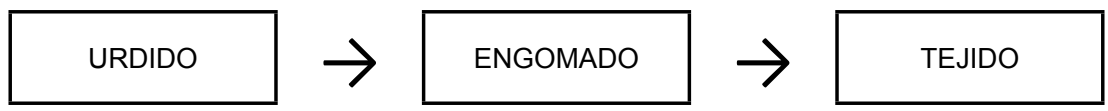

Figura 2. Operaciones principales para elaboración de tela. Fuente: elaboración propia. 
En la Figura 3, se muestran las imágenes de estas tres operaciones básicas para elaboración de la tela en la fábrica de tejido.

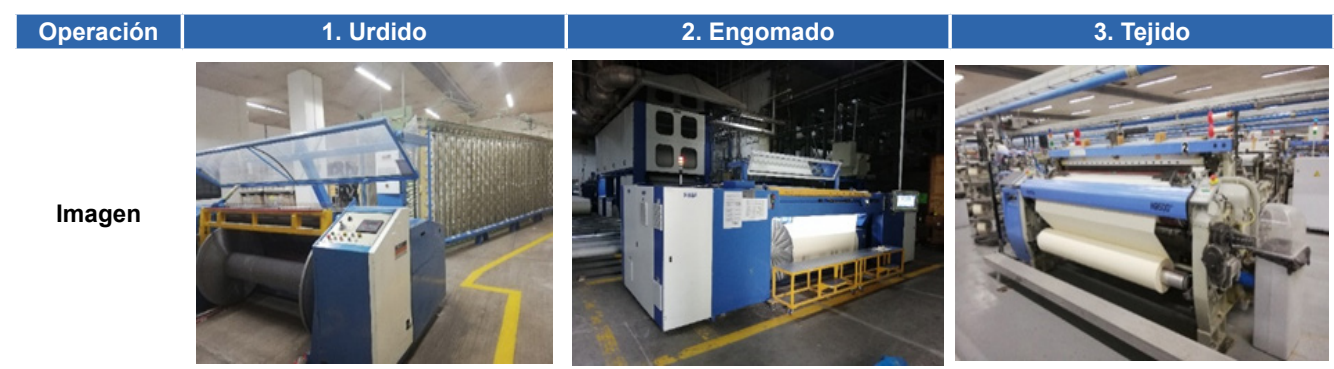

Figura 3. Operaciones básicas para la elaboración de la tela. Operación 1) Urdido, operación 2) Engomado, operación 3 ) Tejido. Fuente: elaboración propia basado en el manual de funcionamiento.

En la operación de urdido (Imagen 1, Figura 3), el hilo llega como materia prima en conos de $30 \mathrm{~cm}$. de altura y de 5000 a 6000 hilos (depende de tela a producir), se enrollan en los denominados "julios".

Una vez preparado un "julio", pasa a la operación de engomado, el cual es una preparación de plastificado que se le proporciona al hilo para darle características necesarias como resistencia y fluidez que requiere la siguiente operación (tejido); en la fase de engomado básicamente se desenrolla y enrolla el hilo de un julio a otro, pasándolo por unas tinas que contienen la sustancia líquida que "moja" al hilo (Imagen 2, Figura 3), dejándolo preparado y listo para el tejido que es la última operación del proceso de elaboración de tela;

La operación de tejido (Imagen 3, Figura 3) es donde se obtiene la tela de aproximadamente dos metros de ancho y en carretes con 300 metros lineales en promedio, en el área de tejido se cuenta con 94 máquinas tejedoras, cada una con las características como se indica en la Tabla 1.

Tabla 1. Maquinaria en la operación de tejido.

\begin{tabular}{|c|c|c|c|c|}
\hline Descripción & Cantidad & Características & $\begin{array}{c}\text { Producción promedio } \\
\text { diaria x maq. }\end{array}$ & Modelo \\
\hline $\begin{array}{c}\text { Máquina de tejer, marca } \\
\text { Sulzer Ruti P7100 }\end{array}$ & 46 & 440 V, 40 A & $280 m$ & 1993 \\
\hline $\begin{array}{c}\text { Máquina de tejer, marca } \\
\text { Sulzer Ruti P7300 }\end{array}$ & 2 & 440 V, 40 A & $360 m$ & 2011
\end{tabular}




\begin{tabular}{|c|c|c|c|c|}
\hline Descripción & Cantidad & Características & $\begin{array}{c}\text { Producción promedio } \\
\text { diaria x maq. }\end{array}$ & Modelo \\
\hline $\begin{array}{c}\text { Máquina de tejer, marca } \\
\text { ITEMA (Neumática) }\end{array}$ & 46 & $220 \mathrm{~V}$ & $450 \mathrm{~m}$ & $\begin{array}{c}2015 \\
\text { (30 maq. y 2018 16 maq.) }\end{array}$ \\
\hline Total & $\mathbf{9 4}$ & & $\mathbf{3 4 , 3 0 0 m}$ Teór. & \\
\hline
\end{tabular}

El total de máquinas en la Fábrica de tejido plano es de 119 incluyendo las que realizan las operaciones de urdido, engomado, tejido y las máquinas de apoyo ubicadas en instalaciones especiales, tales como electricidad, aire comprimido y ventilación; que se utilizan en todas las operaciones.

Se hizo un cálculo de producción promedio diaria correspondiente al primer semestre del 2018, obteniendo la cantidad de $\mathbf{9 5 2 1} \mathbf{m}$ de tela, por lo que comparándola con su producción teórica de tela y en caso de que toda la planta estuviera operativa su producción diaria sería de 3.6 veces más. Actualmente la producción promedio aumentó tomando algunas acciones como es el reemplazo de algunas máquinas de tejido, sin embargo, el problema de fondo, se puede atribuir principalmente a máquinas fuera de servicio, trabajos de mantenimiento o problemas humanos para su funcionamiento. Por el número de máquinas en actividad, se estima que esta operación de tejido, consume la mayor parte de los recursos operativos incluyendo los de mantenimiento (Olarte,2010).

Un aspecto imprescindible en esta temática es el conocimiento de mantenimiento; en la fábrica, pues como ejemplo podemos citar la forma de reclutar técnicos al mantenimiento, en la que al ingresar al equipo de mantenimiento, es necesario que el técnico posea conocimientos técnicos de los sistemas en la maquinaria, que haya sido operario de la misma o si es de reciente ingreso que tenga un nivel aceptable de conocimientos en las ciencias fisicas e ingeniería, o posea alguna especialización técnica, electricidad, maquinas herramienta, mecánica, fontanería, electrónica e informática. Actualmente se tienen 10 reparadores para toda la fábrica, lo que significa que la fábrica cuenta con un técnico por cada una de las áreas citadas, en algunas como se puede notar se carece de él, como es el caso de electrónica e informática muy necesario actualmente (Cárcel, 2014).

Aunque respecto a la capacitación en la fábrica, se procura que siempre se impartan cursos tales como mantenimiento industrial, electrónica y relacionados, sin embargo, observa que carecen de efectividad ya que la demanda del mantenimiento es tal que a veces es necesario atender el correctivo, utilizando las herramientas básicas con que cuentan, consultando únicamente los manuales de funcionamiento y aprender sobre la práctica, o simplemente por carecer de personal disponible para impartirlo. 
Lo anterior, pone de manifiesto la necesidad de contar con más técnicos para cubrir estas deficiencias, en principio cubriendo las áreas señaladas y después para gestionar eficientemente el mantenimiento, es decir preparar y colocar técnicos en áreas nuevas, con un programa de capacitación continua en los principios de funcionamiento, uso de herramienta adecuada, equipo especial y procedimientos de mantenimiento recientes, como la aplicación del predictivo en la maquinaria (Cárcel, 2014).

El abastecimiento de refacciones en la fábrica, es un punto importante de tocar, pues tiene su problemática, un ejemplo es la carencia de refacciones de alto costo, por no ser redituable su almacenamiento o la falta de uniformidad para su plena identificación por no tener un nombre genérico para todos los implicados en el proceso; aunado a la evolución de los modelos de maquinaria, que implican cambios en algunas partes o sistemas, volviendo obsoleto o incompatible la refacción con el modelo anterior y haciendo más difícil de adquirirla.

Por lo cual al este punto se le debe poner especial atención, en todos los niveles de la organización, para que haya coordinación y colaboración total; ya que un mal funcionamiento repercute en todo el sistema y este a su vez en su rentabilidad, de lo que se deduce que la responsabilidad y atención debe ser puesta en todos los niveles desde el operativo (usuario de la máquina) hasta el estratégico (dirección), pasando por mantenimiento en iguales condiciones, si se pretenden mejores resultados globales (Nahmias, 2007).

\section{MÉTODOS DE MANTENIMIENTO Y SU EVOLUCIÓN}

Cuando todo va bien nadie recuerda que existe. Cuando algo va mal, dicen que no existe. Cuando es para gastar, se dice que "no es necesario". Pero cuando realmente no existe, "todos concuerdan en que debería existir". El propósito en la función de mantenimiento es asegurar que todos los recursos físicos de la empresa cumplan la función para la cual fueron diseñados (Olarte, 2010).

La evolución del mantenimiento se ha adaptado a las necesidades de las industrias, y también ha ido paralelo al avance de la tecnología. Las primeras empresas que existieron estaban conformadas por grupos de personas que tenían que trabajar en cada uno de los pasos del proceso de producción y a su vez reparar las herramientas y las máquinas cuando presentaban alguna falla. Debido a que los trabajadores desarrollaban múltiples oficios, el elaborar un producto terminado para ofrecerlo en el mercado implicaba un alto costo en tiempo y dinero (Tavares, 2014). 
Con el objetivo de eficientar el proceso, las empresas se vieron obligadas a distribuir a sus trabajadores para que se dedicaran a tareas específicas, dichas tareas fueron de dos tipos: Tareas de operación de las máquinas y tareas de reparación de las mismas. Con la llegada de la Primera Guerra Mundial y con la implantación de la producción en serie, instituida por Henry Ford, se implementó un nuevo sistema de organización al interior de su empresa al cual llamó "Producción en cadena". Este nuevo sistema, fue establecido a través de la asignación de responsabilidades organizadas (Figura 4).

Con este nuevo modelo, surge el concepto de mantenimiento, el cual dependía del departamento de operación quien era el que determinaba en qué momento se debían realizar las labores de reparación.

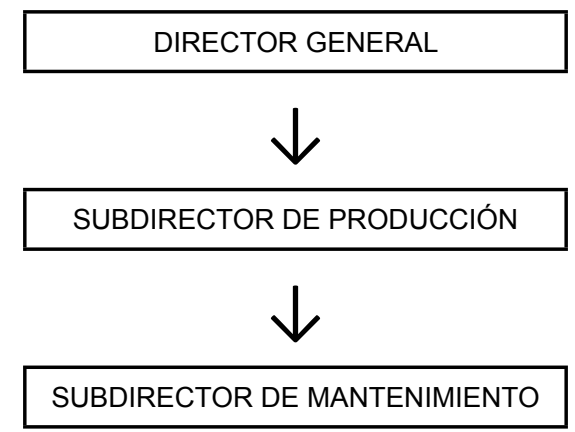

Figura 4. Modelo organizacional, década de 1920. Fuente: elaboración propia basado en (Olarte, 2010).

Con la Segunda Guerra Mundial, las empresas tuvieron que aumentar su producción para cumplir la demanda; para esto, fue necesario incrementar las jornadas laborales. Esta manera apresurada de producir en grandes cantidades y por largos periodos de tiempo hizo que las máquinas se desgastaran más rápido debido al exceso de uso y por lo tanto presentaran fallas en su funcionamiento.

La reparación de las máquinas implicaba la parada del proceso de producción lo cual generaba grandes pérdidas. Con el fin de evitar estas paradas, los empresarios le dieron una mayor importancia al mantenimiento reestructurando su organización (Figura 5). A partir de entonces, el mantenimiento se vuelve una herramienta fundamental para las empresas y se convierte en una actividad correctiva, de mayor importancia para elevar la productividad (Tavares, 2014). 


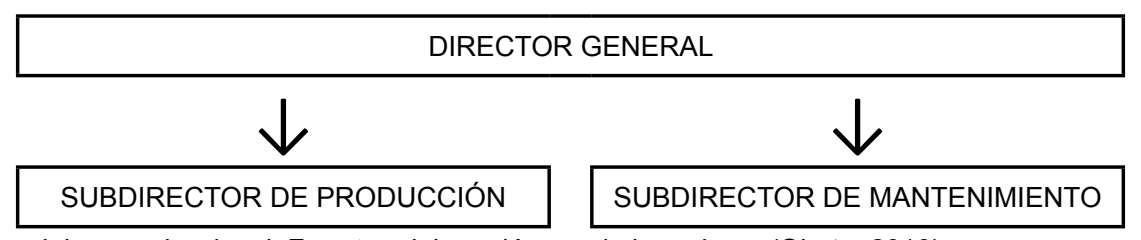

Figura 5. Nuevo modelo organizacional. Fuente: elaboración propia basado en (Olarte, 2010).

Por lo que respecta a su evolución, pueden observarse tres generaciones en la evolución de la función del mantenimiento (Figura 6); después de los años 60 del siglo pasado, se implementaron varios sistemas de mantenimiento industrial tales como Mantenimiento productivo total (TPM) en el cual, como acción estratégica, se involucra a todo el personal de la fábrica en actividades que inciden directamente en el mantenimiento. Mantenimiento centrado en la confiabilidad (RCM), se basa más en información de todo tipo en la maquinaria y mediante listas de verificación se lleva un control de su funcionamiento e historial de fallas, desde piezas hasta sistemas (Garrido, 2014).

Por los costos elevados del correctivo y por lo que representa económicamente una maquina o equipo sin trabajar se han desarrollado nuevas técnicas, métodos y herramientas enfocados a tratar de tener cero paros y defectos en los procesos de productos o servicios de que se trate.

\begin{tabular}{|c|c|c|}
\hline & & TERCERA GENERACIÓN \\
\hline & & $\checkmark \quad$ Mayor disponibilidad y fiabilidad de la planta. \\
\hline & & $\checkmark \quad$ Mayor seguridad. \\
\hline & SEGUNDA GENERACIÓN & $\checkmark \quad$ Mejor calidad del producto. \\
\hline & $\checkmark$ Mayor disponibilidad de la planta. & $\checkmark \quad$ Sin daño al ambiente. \\
\hline PRIMERA GENERACIÓN & $\checkmark \quad$ Mayor tiempo de vida del equipo. & $\checkmark \quad$ Mayor tiempo de vida del equipo. \\
\hline$\checkmark$ Arreglar cuando se rompa & $\begin{array}{ll}\checkmark & \text { Costos más bajos. } \\
\checkmark & \text { PREVENTIVO, TPM, RCM }\end{array}$ & $\begin{array}{ll}\checkmark & \text { Elevado costo de eficiencia } \\
\checkmark & \text { MEJORA DE TÉCNICAS DE } \\
& \text { MANTENIMIENTO Y GESTIÓN DE } \\
& \text { ACTIVOS (PREDICTIVO) }\end{array}$ \\
\hline $1940-1950$ & $1960-1980$ & $1981-2000$ \\
\hline
\end{tabular}

Figura 6. Evolución del mantenimiento. Fuente: elaboración propia basado en (Rojas, 2012). 
Considerado la segunda generación, las empresas se dieron cuenta de la necesidad de crear un área responsable y que asegure que la productividad de la planta no se vea afectada por alguna falla o algún paro no deseado del equipo, porque uno de los gastos más importantes era por falta de esta actividad, además de que los costos por mantenimiento ocupaban el primero o segundo lugar de los gastos operativos.

Entonces algunas de las responsabilidades que se atribuyeron al área de mantenimiento fueron, reducir el tiempo de paralización de los equipos, reparación en tiempo oportuno, garantizar el funcionamiento continuo del equipo y que los productos no se salieran de los límites y estándares establecidos por control de calidad (Tavares, 2014).

Una Técnica más utilizada en mantenimiento y considerada una revolución en la manufactura de los procesos en línea es el SMED "Single Minutes Exchange of Dies" que se traduce como "pequeños minutos en el intercambio de piezas o moldes". Esta metodología de trabajo fue desarrollada por el ingeniero Shingeo Shingo (en los años 70), quien fue uno de los líderes en las prácticas de manufactura en el sistema de producción de Toyota y en donde se aplicó en toda su extensión el TPM. Se le atribuye el haber creado el cero defectos y el Poka Yoke (a prueba de errores). Shingeo refuerza todos los procesos basándose en las herramientas de Ingeniería Industrial tales como: Ingeniería de Métodos, Medición y estudio del trabajo, para obtener el máximo provecho y reducir los tiempos fuera de servicio de las máquinas. También aplicó estas herramientas al proceso de manufactura de producción en línea, pero también este método es posible aprovecharlo para aplicarlo en el mantenimiento en una planta, reduciendo los tiempos de intervención para actividades de ejecución, aumentando de esta manera la disponibilidad y confiabilidad de los activos, (Olarte, 2010).

Shingeo refuerza todos los procesos basándose en las herramientas de Ingeniería Industrial tales como: Ingeniería de Métodos, Medición y estudio del trabajo, para obtener el máximo provecho y reducir los tiempos fuera de servicio de las máquinas.

Por otra parte, considerándose en la tercera generación, en 1992 nació en Inglaterra el concepto gestión de activos (asset management), lo cual dio lugar al establecimiento de grandes y eficientes empresas. Incluyendo estudios que han permitido ver con claridad que toda la actividad existente en el universo sea natural o humana; forma un sistema y éste debe ser administrado como la naturaleza lo hace en forma 
ecológica, a este estudio se incorpora el mantenimiento como parte del activo para gestionar su vida útil. Con esto el pensamiento moderno de la gestión de activos llega a la gestión ecológica de sistemas, considerándose este aspecto dentro de la seguridad, salud humana y ambiental. tema de actualidad, que ha despertado mayor interés (Santini, 2019).

Alrededor del año 2000 surge el concepto de mantenimiento predictivo, que son las acciones de mantenimiento, basadas en las condiciones de un equipo; para prevenir la ocurrencia de fallas. La forma planificada requiere de una programación periódica, teniendo en cuenta las recomendaciones técnicas del fabricante y el histórico de fallas de los equipos (Olarte, 2010).

El mantenimiento predictivo se describe mejor como un proceso que requiere tanto de la tecnología como de las capacidades humanas, durante el uso de una combinación de todos los datos disponibles de diagnóstico y rendimiento, historial de mantenimiento, registros del operador y los datos de diseño para tomar decisiones oportunas sobre los requisitos de mantenimiento de los equipos críticos y maquinaria en general, en general se le puede considerar una continuación del RCM (Olarte, 2010).

La fábrica o cualquier otra empresa puede introducir como se está dando actualmente en otras áreas, el concepto de tecnología 4.0 y aplicarlo también al mantenimiento, aprovechando la era digital en el campo industrial, para gestionarlo como parte de la cadena de valor de los activos, realizando tareas entre otras tales como, registrar funcionamiento en tiempo real de los equipos (Big. Data), predecir y simular perfiles de vida a componentes o sistemas, pronosticar fallas basadas en la condición, coordinar trabajos conjuntos con producción y operación, crear nuevos roles para el personal en la interacción hombre-máquina-planta, y calcular continuamente los indicadores (KPI'S) para mejorar la productividad (Santini, 2019).

Como una evolución de la planificación periódica de las actividades de mantenimiento, se está incorporando el concepto de mejoramiento de los equipos (rediseño), con el propósito de evitar que se produzcan fallas, aprovechando el conocimiento de los operarios e ingenieros en posición de usuarios. Como resultado nace un plan de mantenimiento relacionado con mejoras incrementales (Mulder, 2016), sin embargo esta opción se coloca cuando las fallas son recurrentes en un periodo corto de tiempo, se realiza en los niveles más altos del mantenimiento y con personal multidisciplinario y especialista que si tengan las fábricas; es aplicable cuando la organización ya tuvo experiencia e implantó todos los métodos de mantenimiento anteriormente descritos. 


\section{OBJETIVOS ESTRATÉGICOS DEL MANTENIMIENTO APLICADO A LA INDUSTRIA TEXTIL Y MÉTODOS DE MEJORA}

La tarea de mantenimiento es compleja, toda organización y los involucrados deberán tomarla en cuenta y prestarle la atención que requiere, si desean obtener resultados satisfactorios; por lo tanto. Una buena programación del mantenimiento, aplicada a una industria textil, debería cumplir los siguientes objetivos estratégicos:

A. Elaboración de productos de alta calidad y a bajo costo.

B. Satisfacción de los clientes con respecto a la entrega del producto en el tiempo acordado o sin retrasos.

C. Reducción de los riesgos de trabajo ocasionados por el mal estado de las máquinas.

D. Disminución de costos provocados por paradas del proceso de producción cuando se presentan reparaciones imprevistas.

E. Detección de fallas producidas por el desgaste de piezas permitiendo una adecuada programación para reparación.

F. Evita los daños irreparables en las máquinas y con esto alarga la vida útil del activo.

G. Facilita la elaboración del presupuesto acorde con a las necesidades de la empresa.

Una gestión efectiva del mantenimiento supone, una de las actividades a las que se le debe de dar importancia en las empresas con activos físicos. Por ello es lógico pensar que los esfuerzos deben orientarse a optimizar su funcionamiento y mejorar la productividad, involucrando para tal fin a todos los recursos humanos, técnicos, económicos y materiales (Nahmias, 2007).

En el análisis para la adecuada gestión del mantenimiento, se deberían tener en cuenta los pasos que se realizan para obtener los objetivos estratégicos tales como:

A. Registrar y analizar el estado actual del mantenimiento en la fábrica. 
B. Establecer Variables para medir el desempeño de la fábrica (KPI'S).

C. Basado en los resultados, realizar comparaciones con métodos establecidos.

D. desarrollar un método de mantenimiento involucrando todos sus recursos y lograr su implementación acorde a la naturaleza y problemática que presenta la planta.

E. Continuar los estudios de mantenimiento, registrando con software de esta actividad para continuar analizando el mantenimiento en un ciclo de mejora continua.

Las mejoras necesarias que se podrían implementar tomando como partida el método de mantenimiento actual utilizado en la fábrica de tejido, son:

A. Aumentar el número de técnicos, con el fin de cubrir las deficiencias en las distintas disciplinas del conocimiento (electrónicos, informáticos etc.) y acorde a las áreas a implementar o al nivel que se desee llevar a esta función logística de mantenimiento.

B. Motivar al personal de la fábrica incentivándolos y proporcionándoles mejores instalaciones de servicios ya que se observan que los alojamientos actuales son deficientes, con equidad en los turnos y rotación de puestos en la medida de lo posible.

C. Adquirir y proporcionar mejor equipo y adecuadas herramientas de trabajo, acorde a los nuevos métodos de mantenimiento que se implementen.

D. Mejorar el sistema de abastecimiento de refacciones.

E. Capacitación continua multidisciplinar.

Estas propuestas a implementar en la planta de tejido son las más importantes, pero no deberán olvidarse una vez implementadas, por el contrario, deberán tenerse en consideración en todas las fases de un ciclo de mejora continua (planear-hacer-verificar-actuar) que propuso Edwards Deming (Nahmias, 2007).

Por todo lo anterior se infiere que, las metodologías vistas persiguen básicamente los siguientes objetivos y también es el caso de la fábrica de tejido. 
A. Obtener el máximo de rentabilidad o aumentar la productividad.

B. Disminuir fallas y defectos en los productos (calidad).

C. Seguridad y salud en sus diversos aspectos.

Actualmente no es sencillo implementar alguna mejora en cuanto a mantenimiento, las empresas han evolucionado lentamente conforme a la disponibilidad de sus recursos, y siguen funcionando pensando que el preventivo es mejor, pero a veces, ni el preventivo se lleva a su entera satisfacción, por lo que se ignora esta nueva área de desarrollo que promete dar mucho a cambio de poco.

Lo anterior es solo una breve descripción de lo que es la evolución del mantenimiento en el marco de la ingeniería industrial, se trata de hacer una comparativa con la situación que existe en varias organizaciones, poniendo de manifiesto algunas soluciones en una de las áreas hasta hoy más descuidadas, la de mantenimiento.

\section{CONCLUSIONES}

Con base en lo escrito, es posible concluir que en especial en todo tipo de industrias o edificios con activos físicos, y en particular aplicado a industrias textiles:

A. El mantenimiento es un factor vital que influye en la productividad.

B. La organización del mantenimiento en este caso particular, requiere ser reestructurado, implantando las mejoras necesarias, como las citadas.

C. El conocimiento en las diversas disciplinas es determinante en el mantenimiento.

D. En cualquier organización se deberán registrar el estado de funcionamiento, mantenimiento y producción en tiempo real, para poder establecer índices y diseñar programas que aumenten la productividad.

E. El mantenimiento debe ser atacado por todos los niveles de la fábrica y desde los estudios de factibilidad de cualquier proyecto a implementar. 
F. Existe interés por este tema a nivel mundial, en sus diversos enfoques; siendo complejo por naturaleza, por tal motivo, su evolución ha sido lenta. 


\section{REFERENCIAS BIBLIOGRÁFICAS}

Cárcel, F. J. (2014). La Gestión del conocimiento en la ingeniería del mantenimiento Industrial . Valencia, España: UPV.

Garrido, S. G. (2014). Manual práctico para la gestión eficaz del mantenimiento industrial . Madrid, España: RENOVETEC.

Mulder, W. (2016). Maintenance Ingeeniering. University, Twente, pp.5-13.

Nahmias, S. (2007). Análisis de la producción y las operaciones. Gd. de México: Mc Graw Hill.

Olarte, W. (2010). Importancia del mantenimiento industrial dentro de los procesos de producción. Scientia et. Technica, pp. 354-356.

Rojas, A. J. (2008). Modelo de productividad de David Sumant aplicado a una empresa del sector de maquinaria no eléctrica. Academia y Desarrollo, pp. 81-87.

Santini, F. (2019). Las nuevas fronteras de la función mantenimiento. Mantenimiento, pp. 6-13.

Tavares, L. A. (2014). Administración Moderna del Mantenimiento. Pereira, Brasil: Novo Polo publicacioes. 
/04/ 


\section{CÓMO APLICAR "VALUE STREAM MAPPING" (VSM) HOW TO APPLY "VALUE STREAM MAPPING" (VSM)}

Mónica García Cantó

Ingeniera en Organización Industrial, Ingeniera Técnica en Química por la Universitat Politècnica de València.

E-mail: monigc22@gmail.com

Antonio Amador Gandia

Máster en Organización y Logística por la Universitat Politècnica de València. Ingeniero Técnico de Obras Públicas, Ingeniero Civil por la Universidad de Alicante.

E-mail: tonoamador8@gmail.com

Recepción: 01/04/19 Aceptación: 04/06/19 Publicación: 14/06/19

\section{Gitación sugerida:}

García Cantó, M. y Amador Gandia, A. (2019). Cómo aplicar "Value Stream Mapping" (VSM). 3C Tecnología. Glosas de innovación aplicadas a la pyme, 8(2), pp. 68-83. doi: http://dx.doi.org/10.17993/3ctecno/2019. v8n2e30.68-83 


\section{RESUMEN}

El Value Stream Mapping (VSM) es una técnica desarrollada al amparo del modelo de la Producción Ajustada con el fin de ayudar a las pymes en la mejora de sus procesos productivos.

En esta investigación se han testado las tareas para una perfecta implementación, la selección de áreas críticas y/o familias de productos, mapas de estados actuales, interno y externo, análisis de mudas y desperdicios, para concluir sobre mapas de estado futuros.

\section{PALABRAS CLAVE}

Producción ajustada, Lean manufacturing, Vsm, Mapa proceso, Mejora procesos.

\section{ABSTRACT}

The Value Stream Mapping (VSM) is a technique developed under the model of Adjusted Production to help SMEs in the improvement of their production processes.

In this investigation the tasks for a perfect implementation, the selection of critical areas and / or families of products, maps of current, internal and external states, analysis of changes and waste, to conclude on future state maps have been tested.

\section{KEYWORDS}

Adjusted production, Lean manufacturing, Vsm, Process map, Process improvement. 


\section{INTRODUCCIÓN}

El mapeo de la cadena de valor es una herramienta que te permite la representación gráfica del estado actual y futuro del sistema de producción, con el objetivo de que los usuarios tengan un mejor entendimiento de las actividades de desperdicio que necesitan ser eliminadas.

Esta herramienta potente y sencilla, alinea y distingue el verdadero valor del producto como ninguna otra herramienta. El punto fuerte de esta herramienta es su utilidad y su simplicidad.

\section{METODOLOGÍA}

Los pasos de la implementación del mapeo de la cadena de valor son:

- Selección de un área crítica productiva

- Preparación del mapa del estado actual

- Revisión documentación existente

- Identificación procesos principales

- Definir qué datos hacen falta y deben recopilarse

- Recoger la información

- Análisis del mapa del estado actual

- Mapa del estado futuro

- Cálculo del Tack Time

- Establecer tiempo deseado

- Implementación de herramientas de mejora 


\subsection{SELECCIÓN DE UN ÁREA CRÍTICA O DE UNA FAMILIA DE PRODUCTOS}

Si se quiere realizar el mapeo de todos los productos elaborados en una empresa resultará complicado y con elevado riesgo de error. Es por ello necesario focalizar el proceso de mapeo en una única familia de productos.

Una familia de producto es el conjunto de productos que comparten pasos similares de proceso, equipos comunes y tienen aproximadamente la misma carga de trabajo.

En ocasiones puede resultar complejo encontrar las familias de productos de nuestra empresa.

Una de las técnicas más simples y útiles es elaborar una tabla con los diferentes productos así como los equipos y pasos necesarios para la realización de cada uno de estos, como ilustramos en el siguiente ejemplo.

\begin{tabular}{|c|c|c|c|c|c|c|c|c|c|c|}
\hline & \multicolumn{8}{|c|}{ FASES DEL PROCESO PRODUCTIVO } & \\
\hline & & 1 & 2 & 3 & 4 & 5 & 6 & 7 & 8 & \\
\hline \multirow{7}{*}{ 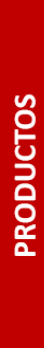 } & A & $\mathrm{X}$ & $x$ & $\mathrm{X}$ & & $x$ & $x$ & & \multirow{5}{*}{$\mathrm{x}$} & \multirow{3}{*}{ Familia de productos $A$} \\
\hline & B & $x$ & $x$ & $x$ & $x$ & $x$ & $x$ & & & \\
\hline & C & \multirow[t]{3}{*}{$\mathrm{X}$} & $x$ & $\mathrm{x}$ & & $\mathrm{x}$ & $x$ & $x$ & & \\
\hline & D & & $x$ & $\mathrm{X}$ & $x$ & & & $x$ & & \multirow{2}{*}{ Familia de productos $B$} \\
\hline & $\mathbf{E}$ & & $\mathrm{x}$ & $\mathrm{X}$ & $x$ & & & $X$ & & \\
\hline & $\mathbf{F}$ & $x$ & $\mathrm{x}$ & $\mathrm{x}$ & $x$ & & & $x$ & $x$ & \multirow{2}{*}{ Familia de productos $C$} \\
\hline & G & $\mathrm{x}$ & $x$ & $x$ & $x$ & & & & $x$ & \\
\hline
\end{tabular}

Figura 1. Mapeo productos. Fuente: elaboración propia.

\subsection{MAPA DEL ESTADO ACTUAL}

La primera pregunta a contestar es: ¿Por dónde empezamos este mapeo y cómo funciona?, para empezar a desarrollar el mapa, se requiere dibujar una serie de iconos de los cuales cada uno tiene diferentes significados y aplicaciones en las diferentes etapas de la cadena de valor.

Los principales símbolos son: 
Fuentes externas: Este símbolo representa clientes y proveedores.

Flecha de traslado: Este símbolo representa el traslado de materias primas y producto terminado. De proveedor a planta o de planta a cliente.

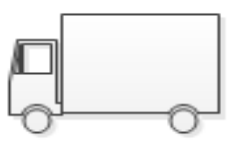

Transporte mediante camión de carga.

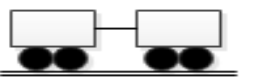

Transporte mediante tren.

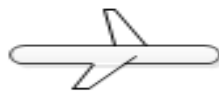

Transporte mediante avión.

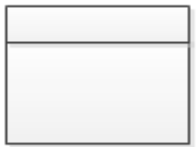

Operación del proceso.

Información: Pronóstico, plan de producción, programación.

Casillero de datos con indicadores del proceso. 

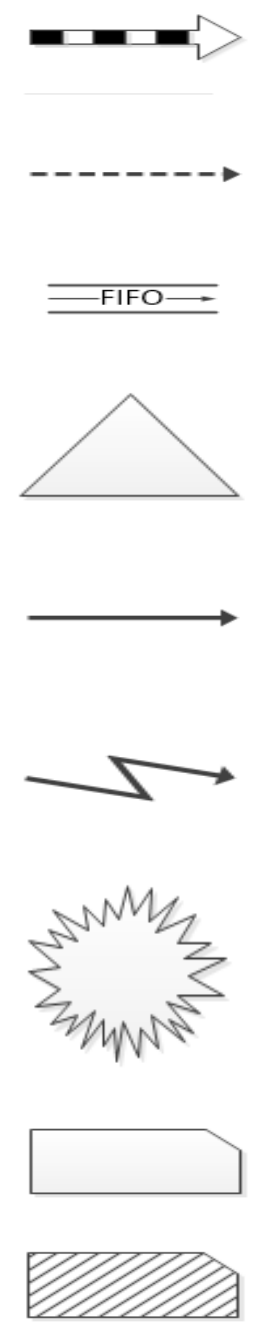

OXOX
Flecha de empuje para conectar el flujo de materiales entre operaciones cuándo este se lleva a cabo mediante un sistema push.

Flecha de arrastre para conectar el flujo de materiales entre operaciones cuándo este se lleva a cabo mediante un sistema pull.

Flecha para conectar el flujo de materiales entre operaciones cuándo este se lleva a cabo mediante una secuencia: "primeras entradas, primeras salidas"

Inventario: De materia prima, producto en proceso, producto terminado.

Información transmitida de forma manual.

Información transmitida de forma electrónica.

Relámpago Kaizen: Este símbolo representa los puntos dónde deben realizarse eventos de mejora enfocado en implementar la herramienta de Lean Manufacturing expresada.

Kanban de producción.

Kanban de transporte.

Nivelación de la carga: Herramienta que se emplea para interceptar lotes de Kanbans y nivelar el volumen de la producción. 
Línea de tiempo: Muestra los tiempos de ciclo de las actividades que agregan valor, y los tiempos de las actividades que no agregan valor.

\subsection{PREPARACIÓN DEL MAPA DEL ESTADO ACTUAL (MAPA EXTERNO)}

Se empieza el mapa dibujando un icono de una empresa y un cuadro de datos en la esquina de arriba del lado derecho del papel. Se llena la caja de datos con la lista de requerimientos del cliente, como unidades por día, numero de cambios, complejidad y otra información de producción.

El próximo paso es delinear los procesos de producción básicos de los proveedores. Usa una caja de datos en el lado izquierdo del mapa para representar a los proveedores. Usualmente no se pueden listar todos los proveedores, por lo tanto se usan los de mayor impacto por cantidad de compra, unidades o importe. Esta información debe de estar disponible para el departamento de compras.

El último paso para el mapeo externo es dibujar los iconos apropiados basados en el tipo de flujo de información. La figura que acompañamos tiene un flujo de información electrónica que son indicadas con líneas que aparecen como relámpagos. Debajo de cada icono de información dibuja una caja de datos de descripción y llena en la frecuencia del flujo de información. Con esto el mapa externo está completo.

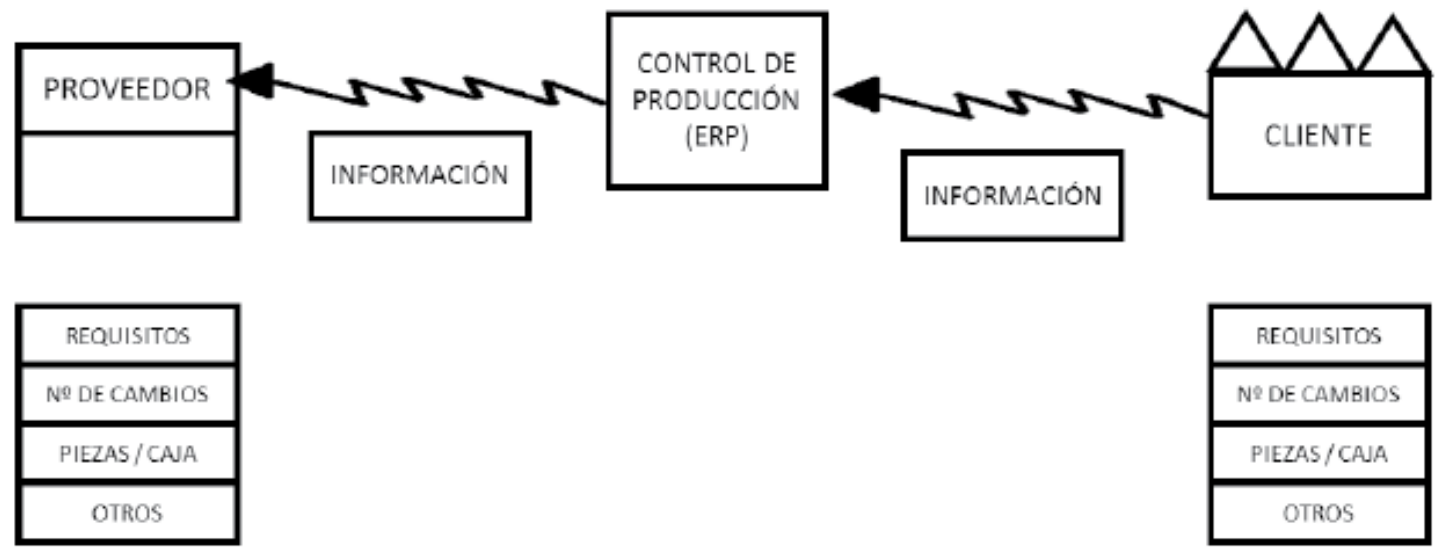

Figura 2. Flujo de información electrónica. Fuente: elaboración propia. 


\subsection{PREPARACIÓN DEL MAPA DEL ESTADO ACTUAL (MAPA INTERNO)}

El equipo debe de hacer la transferencia del mapa del estado externo al mapa del estado interno. La llave del mapa del estado interno es que todos los miembros del equipo se vayan fuera de sus sillas y observen la producción desde el piso para tener una mejor información del proceso y los problemas que puedan existir.

El mejor lugar para empezar es el departamento de envíos o expediciones. El equipo se deberá partir en pequeños grupos y documentar todos los procesos en orden inverso, ya que de esta manera se entienden mejor los flujos y se construye mejor la información del proceso productivo, incluyendo todas las máquinas de proceso, inventario y todos los tiempos de ciclos entre cada proceso de un producto. Una vez que la información ha sido recogida el equipo debe reunirse y dibujar los apropiados iconos en la parte de abajo del mapa.

Otra vez se empieza con el departamento de expediciones y se trabaja de final a principio. Hay que colocar cajas de procesos en el mapa (maquinas, ensambles, pintura, etc.) y agregar cada caja de datos debajo de cada proceso, incluyendo toda la información que el equipo obtuvo del piso de producción.

Después hay que dibujar las cajas del proceso interno, completando el mapa agregando los correctos iconos del flujo de material de un proceso a otro.

El último paso es dibujar una línea de tiempo debajo de cada caja de proceso y triangulo de inventario al esquema del tiempo de espera de producción. La figura que mostramos a continuación es un ejemplo de una producción de tiempo de espera de 4.5 días, un tiempo de valor agregado de 3.9 minutos. El estado actual es ahora terminado.

El mapa del estado actual o mapa interno se crea mediante la colaboración de los diferentes departamentos que componen la empresa. 


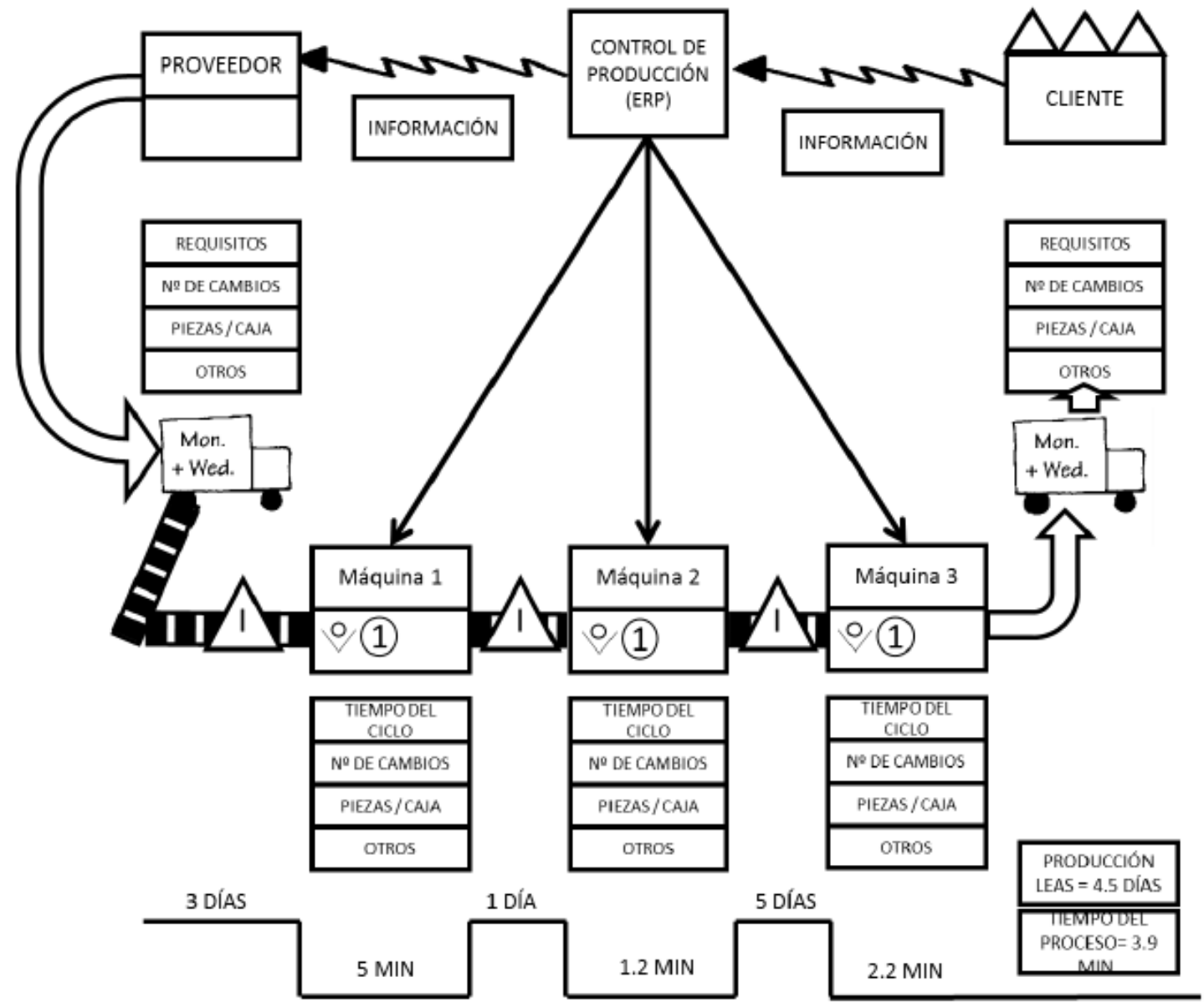

Figura 3. Producción de tiempo de espera. Fuente: elaboración propia. 


\subsection{ANÁLISIS DEL MAPA DEL ESTADO ACTUAL O ANÁLISIS MUDA (DESPERDICIO)}

El principal objetivo al elaborar el mapa de la cadena de valor es la identificación del desperdicio a través del análisis del mismo. Para una fácil eliminación de éstos, fueron clasificados de acuerdo a lo propuesto por Ohno, responsable del sistema de producción Toyota, de la siguiente forma:

- Sobreproducción: es la acumulación deinventarios en manos de las empresas. La sobreproducción es una medida relativa, es la diferencia entre lo producido y lo requerido.

- Espera: Las personas ociosas que esperan inventario son una indicación de que la planta no está balanceada o equilibrada. Todos los trabajadores deben dedicar aproximadamente la misma cantidad de esfuerzo reflejada en tiempo para la eliminación del tiempo de espera.

- Inventario: La producción de inventario que nadie quiere en ese momento, desperdicia espacio, estimula daños y obsolescencias en los productos.

- Transporte: Debe ser fácil y de alta accesibilidad para la fácil adaptación a las exigencias del entorno.

- Sobre proceso: Son actividades innecesarias realizadas en un producto que podrían ser eliminadas sin afectar el valor ni la calidad del producto, todo tipo de sobre proceso es catalogado también como desperdicio y causa un aumento en costos de producción.

- Movimientos: Desperdicio es cualquier movimiento de gente o inventario que no crea valor, así como también una operación con movimientos no ergonómicos que causan fatiga y disminuyen la capacidad de producción.

- Defectos: Errores que requieren rectificación; cualquier trabajo repetido es buena indicación de desperdicio. Un defecto es una actividad o proceso con resultados contrarios a lo especificado. 


\subsection{MAPA DEL ESTADO FUTURO}

El mapa del estado futuro es fácil de desarrollar pero requiere determinación y persistencia para implementarlo. Es decir, el desarrollo del mapa de estado futuro es crítico para proveer una impresión ideal del estado esbelto, ya que en este se proyectan todas las mejoras necesarias para llegar a un resultado ideal. Hay un método para desarrollar el estado futuro.

El primer paso requiere el cálculo del "Takt Time". El "takt time" define cual debe de ser la cadena de salida del producto que adapta la producción a la demanda. Para calcular el "takt time" use la siguiente formula:

\section{Takt time $=($ tiempo neto de operación $/$ periodo $) /($ requerimientos de cliente $/$ periodo $)$}

La importancia del "takt time" es que la meta es producir una unidad justo en el tiempo para remplazar una unidad usada por el cliente, en otras palabras un tiempo de ciclo basado en una pieza a la vez ("onepiece flow"). Reducir el tiempo de ciclo y crear "one-piece flow" dentro del estado futuro del mapa te hace la pregunta: ¿Dónde puede el sistema de producción usar un flujo continuo? Un ejemplo de flujo continuo es automatizar una línea de ensamble.

También podemos cuantificar el estado actual de flujo a través del indicador "Flow Index" (Índice de Flujo), que puede ser entendido como la división del lead time total (TLT) y el tiempo de producción total (MLT):

$$
F I=T L T / M L T
$$

El resultado del estado futuro no significa que sea el final de éste, una vez que es dibujado el estado futuro se analiza el desperdicio del proceso y se revalúa el mapa, se repite este proceso las veces que sea necesario, durante y después del evento.

Después del mapeo del estado futuro habrá que desarrollar un plan de acciones que debe ser seguido, este es creado para hacer la transferencia del estado actual al estado futuro. Un plan extendido de la cadena de valor envuelve eventos Kaizen y revaluación del estado futuro una vez que este ha sido implementado. El mapeo de cadena de valor es una herramienta de comunicación, es una herramienta de planeación de negocios y una herramienta para manejar las empresas. 
Una cadena de valor incluye todas las actividades tanto de valor agregado como las de valor no agregado, así como también las que soportan todas las actividades que son necesarias en la creación de un producto (o servicio) y lo hacen disponible para el cliente. Estas actividades incluyen procesos de operación, flujo de materiales entre el proceso, todas las actividades de control y dirección, así como el flujo de información.

Una medida para determinar el potencial de mejora es determinar la diferencia entre las operaciones y el tiempo de espera. Cuanto mayor sea la diferencia entre operación y tiempo de espera mayor es el potencial de mejora.

Los trabajos de mejora junto al proveedor se pueden iniciarse después de la aplicación del mapa de estado futuro. Hay varias oportunidades para reducir los residuos en la interfaz de productor y proveedor.

Una medida para determinar el potencial de mejora es determinar la diferencia entre las operaciones y el tiempo de espera. 


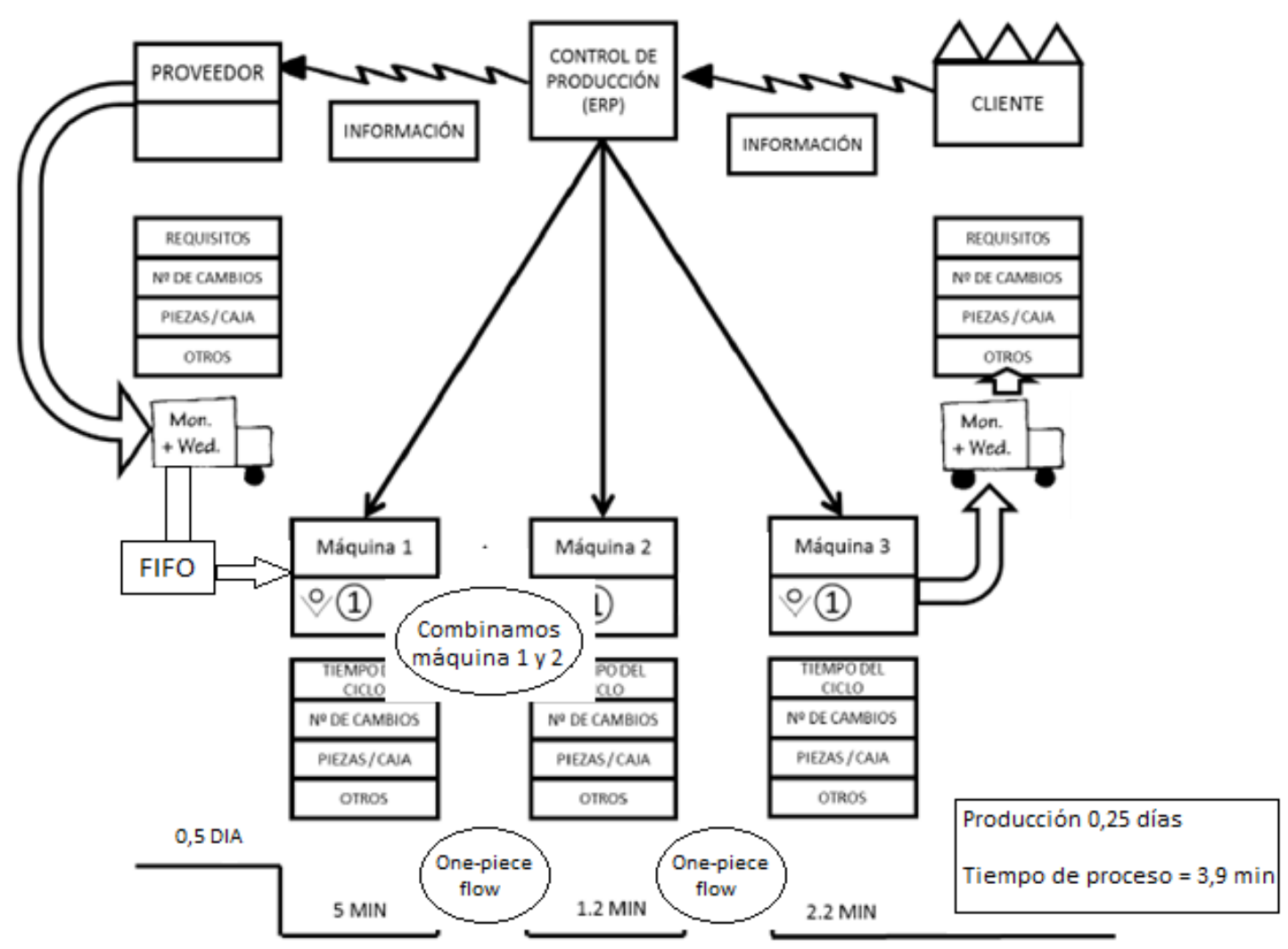

Figura 4. Control de producción. Fuente: elaboración propia.

\section{CONCLUSIONES}

Para reducir el desperdicio y las pérdidas en una cadena de producción, se hace necesario una visión macro del proceso. En este escenario, la herramienta VSM se presenta como una simple y poderosa en la modelaje de un flujo, lo que permite analizar y distinguir los pasos y actividades que se pueden mejorar o eliminar en el proceso. El uso de la VSM permite que la empresa tenga consigo un diagnóstico que permite la mejora continua de la productividad, y de una manera sostenible. 


\section{REFERENCIAS BIBLIOGRÁFICAS}

Lovelle, J. (2001). Mapping the value stream. IIE Solutions, 33(2), pp. 26-33.

López Guevas, B. N. (2013). "Mapeo de la Cadena de Valor" (VSM) como Estrategia de Reducción de Costos. Recuperado de: https://es.scribd.com/document/355387343/Lopez-Guevas

Paciarott, i. G., Giatteo, V., y Giacchetta, G. (2011). Value stream mapping implementation in the third sector. Springer.

Edtmayr, T., Kuhlang, P., y Sihn, W. (2011). Methodical approach to designing workplaces and increasing productivity based on value stream mapping and methods-time measurement. Transactions of FAMENA, 35(1), pp. 91-99.

Vendan, S., y Sakthidhasan, K. (2010). Reduction of Wastages in Motor Manufacturing Industry. Fordan Fournal of Mechanical and Industrial Engineering, 4(5), pp. 579 - 590. 


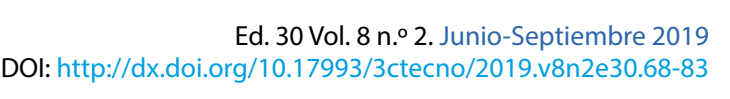


/05/ 


\section{ANÁLISIS DE CAUSA RAÍZ. TÉCNICAS Y RELACIÓN CON LOS SISTEMAS DE GESTIÓN Y LAS NO CONFORMIDADES \\ ROOT CAUSE ANALYSIS. TECHNIQUES AND RELATIONSHIP WITH MANAGEMENT SYSTEMS AND NON-COMPLIANCE}

Jorge Poveda Gatalán

Máster en Dirección de Empresas y Graduado en Ingeniería Mecánica por la Universitat Politècnica de València.

E-mail: jorgepc94xct@gmail.com

Mireia Guardiola Aparisi

Máster en Dirección de Empresas y Graduada en Administración de Empresas por la Universitat Politècnica de València.

E-mail:mireguaap@gmail.com

Recepción: 19/04/19 Aceptación: 31/05/19 Publicación: 14/06/19

Gitación sugerida:

Poveda Catalán, J. y Guardiola Aparisi, M. (2019). Análisis de causa y raíz. Técnicas y relación con los sistemas de gestión y las no conformidades. 3C Tecnología. Glosas de innovación aplicadas a la pyme, 8(2), pp. 84-97. doi: http://dx.doi.org/10.17993/3ctecno/2019.v8n2e30.84-97 


\section{RESUMEN}

En el presente artículo se estudian las técnicas de análisis de causa raíz, su relación con los sistemas de gestión y las no conformidades asociadas para desarrollar las claves para que funciones con éxito un sistema de análisis causa raíz. Se desarrollan de forma pormenorizada las Disposiciones específicas de la metodología de análisis causa raíz, para concluir con las diferentes herramientas.

\section{PALABRAS CLAVE}

Causa Raíz, RCA, ACR, Mejora continua, Análisis de causas.

\section{ABSTRACT}

In the present article the techniques of root cause analysis, its relationship with the management systems and the associated non-conformities are studied to develop the keys for a successful root cause analysis system. The specific provisions of the root cause analysis methodology are developed in detail to conclude with the different tools.

\section{KEYWORDS}

Cause Root, RCA, ACR, Continuous improvement, Analysis of causes. 


\section{INTRODUCCIÓN}

\section{1. ¿QUÉ ES EL ANÁLISIS DE CAUSA RAÍZ?}

Análisis de causa raíz. Análisis de Causa Raíz (ACR o RCA en sus siglas en inglés) es un método para la resolución de problemas que intenta evitar la recurrencia de una incidencia o defecto a través de identificar sus causas.

El análisis de causa raíz se utiliza para investigar cuáles son las causas que han originado un determinado problema o incidencia, poder actuar sobre ellas evitando así su recurrencia en el futuro

\section{2. ¿ES MALO QUE UN SISTEMA GENERE NO CONFORMIDADES?}

Siempre que la cuantía de esas no conformidades se encuentre dentro de límites razonables, puede ser hasta positivo la aparición de éstas, siendo un síntoma de que el sistema funciona de manera adecuada.

Será positivo que el sistema recoja las incidencias y no conformidades siempre que seamos efectivos en su Acción Correctiva, es decir, las actuaciones posteriores a la detección de la no conformidad, en las que se identifica el problema, se determinan las causas que lo producen y se ponen en marcha acciones para eliminar dichas causas y, por ende, el problema no se vuelva a repetir.

De todas estas acciones, el Análisis de Causas suele ser la tarea más importante y la más difícil de llevar a cabo. Si este análisis no se realiza de forma adecuada, si la identificación realizada de las causas es errónea o no adecuada, los esfuerzos posteriores que realicemos en eliminarlas serán en vano o inútiles.

\section{3. ¿ES FÁCIL EL REALIZAR UN ANÁLISIS DE CAUSAS?}

En todas las organizaciones se dan a diario no conformidades que tienen su origen en causas triviales, en las que el análisis de causas es automático, claro, fácil y, por ende, la acción correctiva es evidente. En estos casos no sería necesario el realizar un análisis de causas como tal, ni aplicar las herramientas que después analizaremos.

Por otro lado, hay una parte de las no conformidades en las que no es fácil o trivial el determinar las causas que las produjeron y, en estos casos, si es deseable el apoyarse en las llamadas herramientas RCA. 
Téngase en cuenta, que, dependiendo de su origen y carácter, estas incidencias pueden suponer pérdidas significativas de dinero, o de seguridad, siendo prioritario asegurar que el problema se resuelve correctamente y que no se repetirá en el futuro.

Dependiendo del origen y carácter de la incidencia, esta puede suponer pérdidas significativas de dinero, siendo prioritario asegurar que el problema se resuelve correctamente.

\subsection{LAS CLAVES DEL ANÁLISIS DE CAUSA RAÍZ}

- El análisis será tan bueno o malo como la sea la calidad de la información recopilada. Si entra basura, sale basura.

- Los antecedentes y experiencia a veces pueden ser buenos, a veces malos para realizar un buen análisis de causa raíz.

- Se tiene que entender claramente qué sucedió, cual es el problema. Más tarde intentaremos entender el por qué sucedió.

- A veces, no se pueden resolver al 100\% todos los problemas de desempeño o no conformidades, siendo positivo conformarse con llegar al 60\%, siguiendo la máxima 10\% de esfuerzo para conseguir el 60\% de resultado. Más tarde ya perfeccionarás el método y aumentarás la eficacia de la solución tomada.

- Todas las investigaciones no tienen que ser iguales, pero la estrategia o metodología para hacerlas si puede estar normalizada.

\section{METODOLOGÍA}

A continuación, desarrollamos las etapas de una Metodología de Análisis Causa Raíz (ACR) para identificar las acciones y/o recomendaciones que eliminen las causas de las no conformidades y que ofrezcan rentabilidad o añadan valor al proceso. 


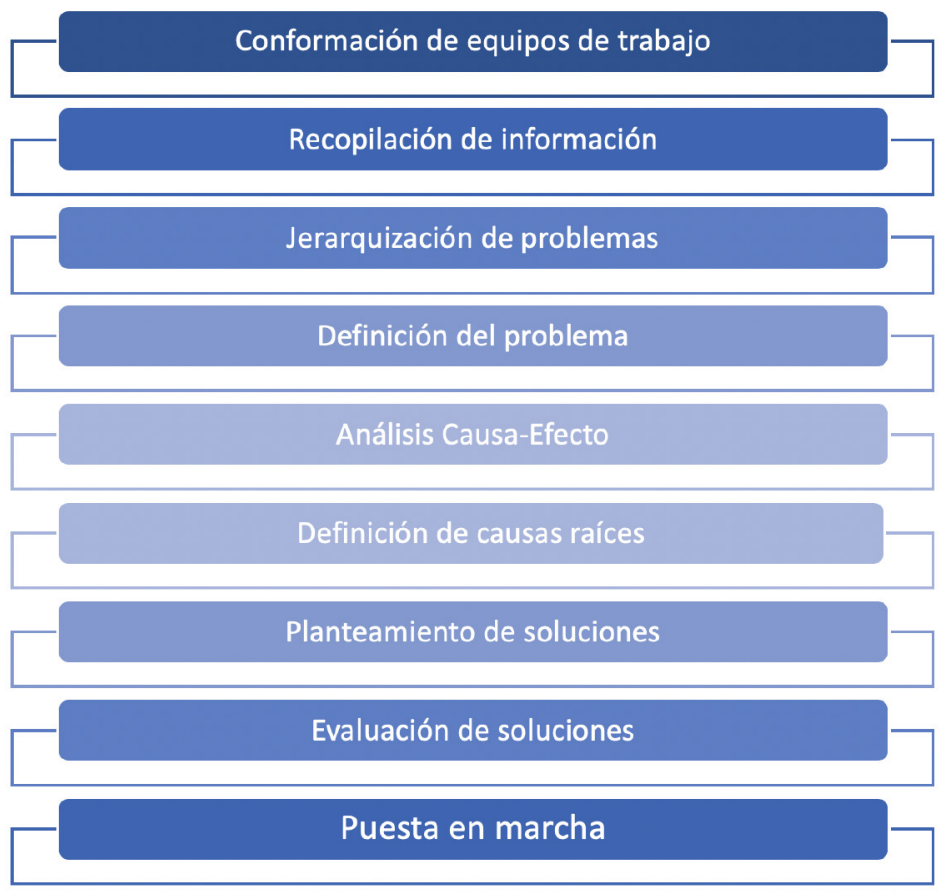

a) Conformación del Equipo de trabajo

El equipo de trabajo puede ser multidisciplinar, dependiendo del alcance del problema, formado por personas de diferentes niveles de responsabilidad.

Deberán tener conocimiento sobre el problema a tratar, en sus diferentes vertientes, así como de los efectos producidos, compuesto normalmente por personal interno de la empresa, apoyado en su caso, por profesionales externos.

Dentro del grupo tendrá que haber personal con conocimiento de:

- Gestión de reuniones.

- Herramientas de análisis y resolución de problemas. 


\section{b) Recopilación y Tratamiento de Datos}

Todo análisis de un problema se inicia con la recopilación de datos asociados a la no conformidad.

La base de la información podrá devenir, según proceda y dependiendo del problema a tratar, de:

- Diagrama de flujo de procesos,

- Datos de frecuencia de la no conformidad, producción diferida, impacto en seguridad/ ambiente, etc.,

- Manuales de equipos,

- Manuales de operación,

- Condiciones operacionales/tendencias,

- Planes de mantenimiento,

- Información específica sobre la no conformidad: causas inmediatas, estudios previos, fotos, análisis de falla, análisis de laboratorio, entre otros.

c) Jerarquización de problemas

El proceso de jerarquización requerirá determinar el impacto de cada no conformidad. Para ello, una de las técnicas más habituales es sumar los costes de reparación o deshecho de cada no conformidad y el coste de pérdida de oportunidad por la producción diferida. También se puede calcular multiplicando la frecuencia de la no conformidad por la consecuencia de cada una de ellas.

El diagrama de Pareto nos puede ayudar a organizar datos, ya que permite asignar un orden de prioridades, al mostrar gráficamente la existencia de muchos problemas sin importancia frente a unos pocos muy importantes. Hay que tener en cuenta que tanto la distribución de los efectos como sus posibles causas no es un proceso lineal, sino que el $20 \%$ de las causas totales hace que sean originados el $80 \%$ de los efectos. El principal uso que tiene el elaborar este tipo de diagrama es el poder establecer un orden de prioridades en la toma de decisiones dentro de una organización. 
d) Definición del problema

En las sesiones de trabajo, el grupo se cuestionará:

- ¿Cuál es el problema? (enunciado)

- ¿Cómo ocurrió el problema?

- ¿ ¿Dónde ocurrió el problema? y ¿dónde no ocurrió?

- ¿Qué condiciones se presentaron antes de que ocurriera el problema?

- ¿Qué controles o protecciones pudieron prevenir que ocurriera el problema y no lo hicieron?

- ¿Cuál es el impacto del problema en seguridad, ambiente, producción y costos de mantenimiento?

Se debe describir una breve historia del problema, indicando, a ser posible, el día que iniciaron las operaciones, la fecha en que se detectó el problema, los eventos relevantes antes de esta fecha, como modificaciones del sistema, mantenimientos realizados, cambios en métodos y/o procedimientos, cambios de personal, etc.

\section{e) Análisis Causa-Efecto}

Este método se basa en el hecho de que una no conformidad siempre tiene una causa, y que está a su vez tiene otra causa, convirtiéndose la primera en efecto de la segunda. Dicho de otra manera, una causa siempre se convierte en efecto de otra causa, formándose de este modo una cadena de causas y efectos, que puede continuar hasta llegar a la causa fundamental del problema.

Las principales características del Análisis Causa-Efecto son:

- Se trata de buscar y encontrar las causas de lo que nos sucede, cuando se trata de un problema, pero también se puede plantear de un modo positivo: causas que influyen en la mejora que pretendemos conseguir.

- Una cosa son los síntomas y otra las causas de verdad. 
- La pregunta ¿por qué?, en este caso es clave. Es lo que nos hacen los niños.

- Lleva tiempo.

- Existen causas diversas.

- Conviene que todos digan lo que piensan. El que tenga algo que decir que lo diga ahora..., o calle para siempre. En el fondo, es la plasmación de un análisis que hacemos en ese momento.

- $\quad$ Es importante que quede por escrito.

- Observar los resultados y llegar a un consenso.

f) Definición de Causas Raíces

Podemos distinguir entre:

- Causas Raíces Físicas: Están relacionadas con errores o fallos de los equipos.

- Causas Raíces Humanas: Son el origen de las causas raíces físicas. Son ocasionadas por la intervención inapropiada del factor humano. Generalmente, se relacionan con: descuido, olvido o equivocación

- Causas Raíces Latentes: Son el origen de las causas raíces humanas. Tienen que ver directamente con el sistema organizacional o de administración. Se refiere a la no utilización de procedimientos, fallo de programas, etc.

g) Planteamiento de soluciones

Uno de los pasos más importantes, después de haberse realizado el Análisis Causa-Efecto, es determinar las soluciones que resolverán el problema de forma sustentable, de tal manera que éste no deba repetirse.

Se deberán plantear las acciones necesarias para corregir las causas raíces físicas que provocan el fallo; así como para corregir las causas latentes, que hacen que las personas cometan errores y omisiones, así como la aparición de los problemas organizacionales. 
Es importante enfocarse a corregir las causas latentes y no llevar acciones punitivas con las personas.

h) Evaluación de soluciones

Con el objeto de determinar si las soluciones propuestas son convenientes, es necesario realizar el Análisis Costo-Riesgo-Beneficio, que se refiere a comparar el costo de llevar a cabo las acciones contra el riesgo de seguir perdiendo el costo de las consecuencias si no se hace nada, considerando los beneficios al poner en marcha dichas acciones. Cualquier método de cálculo es válido.

\subsection{HERRAMIENTAS DE ANÁLISIS CAUSA RAÍZ (RCA)}

Conforme hemos comentado en apartados anteriores, estas herramientas son métodos de resolución de problemas dirigidos a facilitar la identificación de sus causas.

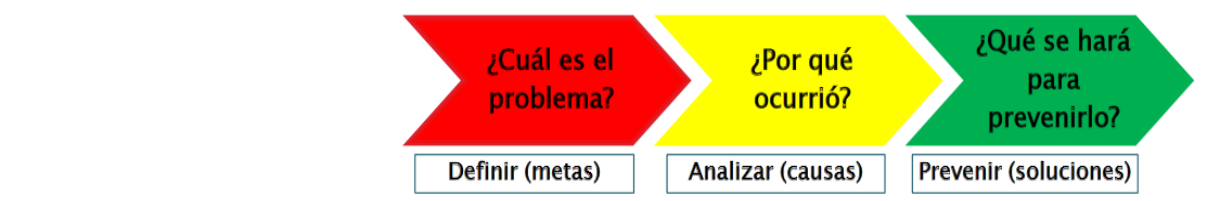

Figura 1. Identificación causas del RCA. Fuente: (Espinosa, s.f.)

Entre las técnicas para el análisis causa raíz, las más utilizadas son:

- Los 5 porqués.

- Diagrama de Ishikawa.

- Análisis de barreras.

- Inferencia Bayesiana.

- Análisis árbol factor causal.

- Análisis de cambios.

- Árbol de la realidad actual (teoría de las restricciones).

- Análisis de los modos de falla y efectos (FMECA). 
- Análisis del árbol de fallas.

- Análisis de Pareto.

- Diagnóstico de problemas RPR (Rapid Problem Resolution).

Las técnicas no son mejores ni peores, simplemente se adaptan o no a una problemática dada.

De modo muy breve, vamos a detallar la técnica de los "Los 5 Porqués" ya que es una técnica fácil y simple de utilizar en causas raíces humanas y latentes.

Esta técnica es un método basado en realizar preguntas para explorar las relaciones de causa-efecto que generan un problema en particular. El objetivo final de los "5 Porqués" es determinar la causa raíz de un defecto o problema.

\section{Para las causas raíces físicas, una de las herramientas más efectivas es el diagrama de Ishikawa.}

El Diagrama de Ishikawa o Diagrama de Causa Efecto (conocido también como Diagrama de Espina de Pescado dada su estructura) consiste en una representación gráfica que permite visualizar las causas que explican un determinado problema.

Su estructura es muy intuitiva ya que identifica un problema o efecto y luego enumera un conjunto de causas que potencialmente explican dicho comportamiento. Adicionalmente cada causa se puede desagregar con grado mayor de detalle en subcausas. Esto último resulta útil al momento de tomar acciones correctivas dado que se deberá actuar con precisión sobre el fenómeno que explica el comportamiento no deseado.

\section{CONCLUSIÓN}

La principal conclusión es que el análisis causa raíz (RCA) es un proceso de gran importancia y rigor técnico para llegar a determinar las verdaderas causas de fallos en elementos de máquina, proceso y procedimiento. 
Se han determinado las disposiciones específicas de la Metodología de Análisis Causa Raíz, para desarrollar las diferentes etapas, acciones y recomendaciones que eliminen las causas de las no conformidades y que ofrezcan rentabilidad o añadan valor al proceso.

Por último, se ha concluido sobre las diferentes herramientas de análisis causa raíz, entendiendo que pueden ser de gran utilidad para enfrentar las diferentes causas independientemente de la tipología del error. 


\section{REFERENCIAS BIBLIOGRÁFICAS}

Escobar, E. (2009). No conformidades, Análisis de Causa y los Cinco ¿Por Qué? (CP). Recuperado de: https:// calidadhoy.wordpress.com/2009/09/26/no-conformidades-analisis-de-causa-los-cinco-porque/

Espinosa, F. (s.f.) Análisis Causa Raíz (RCA). Pequeñas charlas para gestión del mantenimiento. Recuperado de: http:/ / www.academia.edu/15782171/Peque\%C3\%B1as_charlas_para_gesti\%C3\%B3n_del_ mantenimiento_Fernando_Espinosa_Fuentes

Jimeno Bernal, J. (2015). Análisis de causa raíz - Metodología para investigar y resolver incidències. Recuperado de: https://www.pdcahome.com/7642/analisis-de-causa-raiz-metodologia-para-investigar-yresolver-incidencias/

Paradies, M. (2011). 7 Secretos/secretos del análisis de Causa raiz. Recuperado de: https://www.taproot. $\mathrm{com} / 7$-secretos-secretos-del-analisis-de-causa-raiz/

Qué es el Diagrama de Ishikawa o Diagrama de Causa Efecto. (2017). Recuperado de: https://www. gestiondeoperaciones.net/gestion-de-calidad/que-es-el-diagrama-de-ishikawa-o-diagrama-decausa-efecto/ 


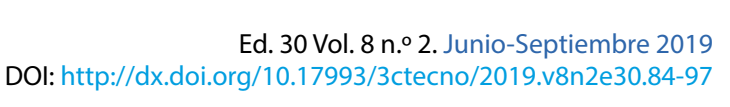




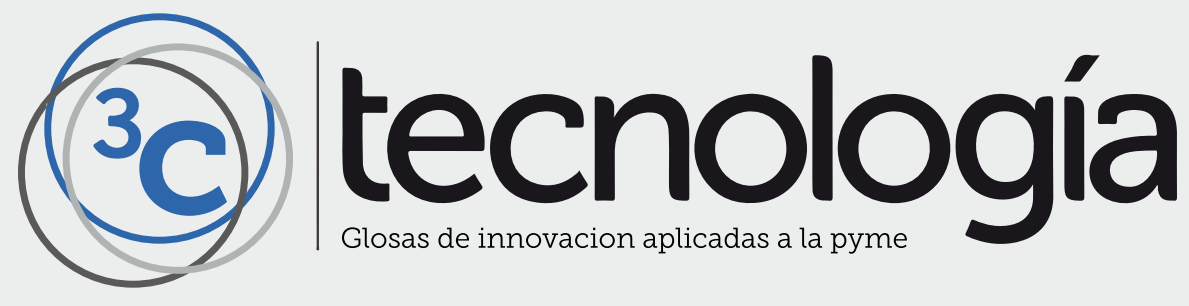

